\title{
Explaining the Evolution of Passenger Vehicle Miles Traveled in the United States
}

\author{
Benjamin Leard, * Joshua Linn, ** and Clayton Munnings ***
}

\begin{abstract}
After growing steadily for several decades, passenger vehicle miles traveled (VMT) in the United States unexpectedly leveled off in the 2000s. The growth rate of VMT has since rebounded, and determining the factors that explain these developments has implications for future U.S. oil consumption and vehicle pollution. We show that changes in the demographics and economic characteristics of households in the United States, rather than in driving habits, explain most of the recent dynamics. This suggests that over the next decade, VMT in the United States will continue to grow roughly at historical rates, causing substantially higher oil consumption and pollution than if persistent changes in driving habits explained the recent changes in VMT. The projected VMT growth will raise the cost of meeting energy security, climate, and local air quality objectives.
\end{abstract}

Keywords: Passenger vehicles, Miles traveled, Demographics, Gasoline consumption, Greenhouse gas emissions

https://doi.org/10.5547/01956574.40.1.blea

\section{INTRODUCTION}

How much people drive their vehicles will play a central role in determining future U.S. oil consumption and pollution. Passenger vehicles account for almost half of U.S. oil consumption, about 15 percent of greenhouse gas emissions, and much of the pollution that reduces local air quality. Mechanically, passenger vehicle emissions depend on vehicle fuels, vehicle emissions rates, and the total vehicle miles traveled (VMT). The United States, like many other countries, sets standards for new vehicles' fuel economy and emissions rates, which determine emissions rates across the entire fleet in the long run. ${ }^{1}$ Via the Renewable Fuel Standard program, federal policy also determines the carbon content of vehicle fuel. VMT depends on policies such as fuel taxes, congestion charges, and decisions of individual drivers. In short, the future path of VMT has implications for energy security, greenhouse gas emissions, and local air quality.

Recent developments have attracted media and public attention to how much people drive their vehicles. After decades of growing at about 2 percent per year, VMT suddenly leveled off in the mid-2000s and by some estimates decreased. The popular media offered a range of hypotheses, in-

1. Under the current standards, the fuel economy and greenhouse gas requirements of each vehicle depend on its size and whether it is a car or light truck. Therefore, the precise level of fuel economy and emissions achieved under the standards depends on the mix of vehicles sold.

* Fellow, Resources for the Future. E-mail: leard@rff.org.

** Corresponding author. Associate professor, University of Maryland and senior fellow, Resources for the Future.

E-mail: linn@rff.org.

*** Senior research associate, Resources for the Future. E-mail: munnings@rff.org. 
cluding household demographics (such as an aging population, since older households tend to drive less) and economic characteristics (such as declining household incomes, rising unemployment attributable to the recession, and rising or volatile gasoline prices). ${ }^{2}$ We refer to such developments as changes in household demographics and economic characteristics. Another set of hypotheses involves changes in how much households drive, conditional on demographics and economic characteristics. For example, the Amazon hypothesis contends that online shopping reduces driving. Another hypothesis is that current younger households (i.e., the millennials, or individuals born after 1980) drive less than younger households in previous generations because of a stronger preference for public transit, virtual connectivity, or other reasons. We refer to these developments as changes in household driving habits, which are defined as the average number of miles driven by groups of households with common demographics and economic characteristics. For example, low-income elderly households typically drive about half as much as high-income elderly households, reflecting a difference in driving habits between these groups.

These possible explanations have differing long-term implications for VMT, oil consumption, and emissions. For example, a persistent change in household driving habits implies that VMT will grow more slowly in the future than it did in the years prior to the 2000s. On the other hand, if the recession was the main factor, expected future economic growth would imply that VMT will rise roughly at historical rates. Whether VMT will be flat or grow at historical rates will have profound effects on U.S. oil consumption and emissions and on the costs of meeting particular energy security or environmental objectives. Comparing these two hypothetical cases, rising VMT would eliminate about half of the savings attributed to U.S. fuel economy standards - that is, an effect much greater than the rebound effect, which has been the focus of the literature (e.g., Gillingham 2014).

This paper explains the slowdown in VMT growth after 2000 and the subsequent recovery and draws implications for future VMT growth and transportation policy. Although a vast body of literature has characterized the effects of income and fuel prices on VMT and gasoline consumption (e.g., Hughes et al. 2008), most of this literature has used aggregated data and assumed linear or log-log relationships among national VMT and average income, fuel prices, and demographics. Such assumptions are necessary given the limited number of observations and the limited data available at the aggregate level. However, as we explain in Section 3, using aggregated data makes it challenging to distinguish changes in driving habits over time from nonlinear relationships among household-level VMT, demographics, and economic characteristics. A few recent studies (e.g., Blumenberg et al. 2012) have focused on possible changes in driving habits among certain demographic groups, such as millennials, but they have not quantified the overall importance of changes in driving habits or the implications of any such changes for future VMT growth. In short, the literature offers little insight on whether changes in demographics and economic characteristics or changes in household driving habits explain the recent slowdown and subsequent recovery in VMT growth.

In this paper, we distinguish between the contributions of demographics and economic characteristics and the contributions of household-level driving habits to changes in national VMT. We begin by estimating the relationships among household VMT, demographics, and economic characteristics in a base year before the VMT slowdown. The large sample of households in our data enables us to estimate nonlinear relationships between VMT and variables such as age or income. Subsequently, we use the Oaxaca-Blinder methodology to decompose changes in total VMT between the base year and any subsequent year into two classes: (a) changes in demographics and

2. http://business.time.com/2012/04/13/off-the-road-8-reasons-why-were-driving-less; https://www.washingtonpost.com/ news/wonk/wp/2013/04/22/why-arent-younger-americans-driving-anymore; http://www.npr.org/2016/02/11/466178523/likemillennials-more-older-americans-steering-away-from-driving 
economic characteristics; and (b) changes in household driving habits, conditional on demographics and economic characteristics. We estimate habits in the base year as the coefficients from a linear regression of household VMT on explanatory variables. The predictions of VMT in years following the base year derive from changes in explanatory variables after the base year. As we show below, the change in predicted VMT between the base year and a subsequent year reflects changes in demographics and economic characteristics. The difference between the actual and predicted change in VMT in any year following the base year reflects the contribution of changes in household driving habits for particular demographic or economic groups - for example, including the differences in typical miles traveled by millennials compared with other cohorts of young adults.

Our first result is that changes in demographics and economic characteristics, rather than changes in household driving habits, largely explain changes in VMT between 1995 and 2015. The microdata that underlie the decompositions suggest the existence of nonlinear relationships between household VMT and the explanatory variables. Aging of the population made a negative but relatively small contribution to changes in VMT between 1995 and 2015, whereas income and the number of workers per household contributed to the VMT changes. Moreover, the increase in number of workers per household after 2010 explains the increase in VMT per household in the 2010s.

Based on our first result, we predict future VMT assuming that demographics and economic characteristics continue to explain VMT and that driving habits of each household group remain persistent. Future VMT will therefore reflect the offsetting contributions of rising income, which increases VMT, and the aging population, which reduces VMT.

Our second result is that we predict average annual VMT growth of about 0.9 percent between 2015 and 2025, which is lower than historical averages although higher than the growth observed during the 2000s. Our predicted growth rate implies that 2025 oil consumption and greenhouse gas emissions will be about 10 percent higher than if VMT were to remain at 2015 levels. If VMT grows at the predicted rate rather than remaining constant, VMT growth will offset nearly half of the reductions in oil consumption and greenhouse gas emissions in the year 2025 caused by fuel economy standards for passenger vehicles.

The results have implications for policies attempting to reduce the greenhouse gas and local air quality problems that passenger vehicles cause. Our analysis implies that VMT growth will increase the challenges of reducing greenhouse gas emissions, local air pollution, and traffic congestion. The projected VMT growth implies that tighter vehicle greenhouse gas emissions standards will be needed to meet climate objectives than if VMT growth were lower. Federal regulations determine air quality standards for various forms of air pollution, such as carbon monoxide, and many urban areas exceed current standards. Because vehicles are major contributors to these problems and federal policy sets emissions rates for new vehicles, state policy makers can target VMT and the emissions rates of older vehicles. Therefore, the conclusion that VMT will grow at nearly historical rates means that it will be harder to achieve local air quality standards.

\section{THE RECENT DECLINE IN VMT GROWTH AND LITERATURE REVIEW}

\subsection{The Recent Decline in VMT Growth}

Between 1975 and 2000, VMT of U.S. passenger vehicles grew steadily and was strongly correlated with income and employment. Figure 1 shows data on VMT per licensed driver, income per capita, and nonfarm employment from EIA (2014), with all variables normalized to equal one in 1975 for comparability. Between 1975 and 2000, VMT per driver grew at an annual rate of about 
Figure 1: VMT, Income, and Employment Trends

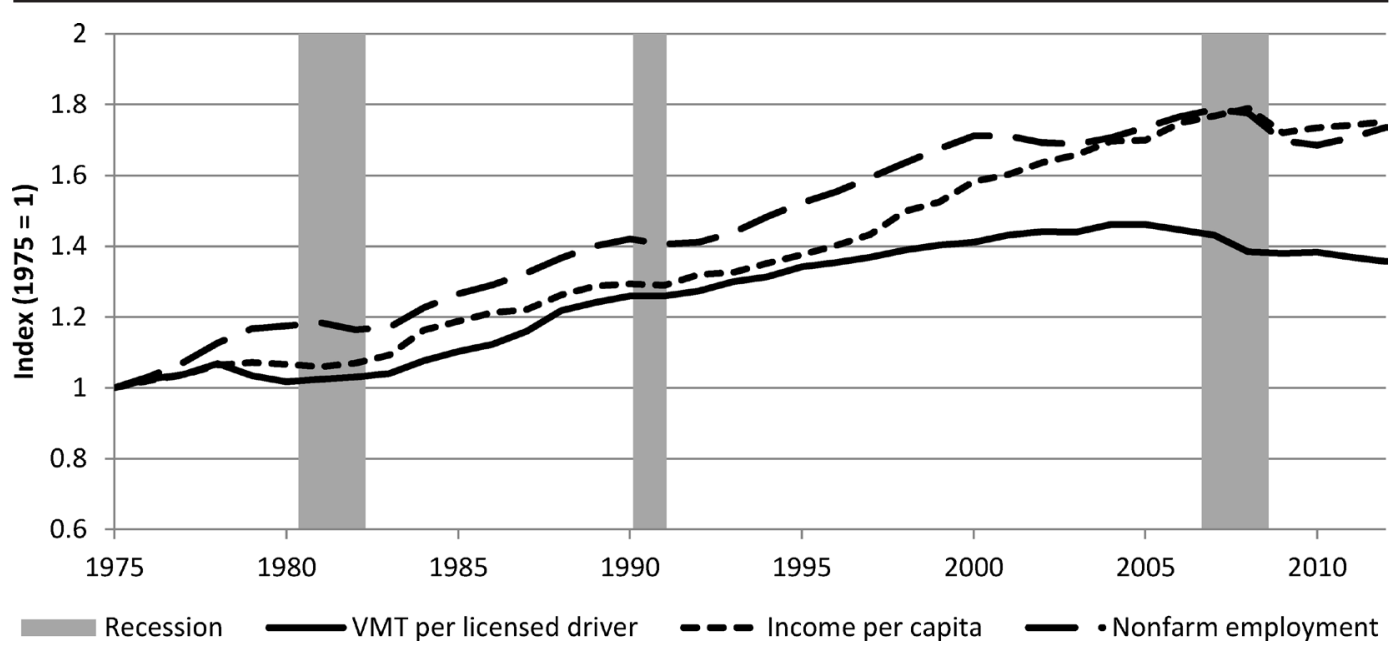

Source: Data are from EIA (2014).

Notes: Vehicle miles traveled (VMT) includes light-duty vehicles. All data series are normalized to one in 1975 . Shaded areas indicate National Bureau of Economic Research recession periods.

1.5 percent, and the graph indicates that periods of rising income and employment are accompanied by rising VMT per driver. Likewise, periods of falling income and employment are accompanied by falling VMT per driver. Before 2000, VMT per driver was positively correlated with income and employment, but after 2000, the correlations between VMT per driver and income and employment were approximately zero. ${ }^{3}$ Although income continued to rise in the $2000 \mathrm{~s}$, VMT per household leveled off and then declined after 2007. Declining employment growth during the 2000s could at least partly explain this decoupling, but after 2000, VMT per household and employment were weakly correlated with one another. This graph suggests that the relationship between average income and VMT differed between the 2000s and earlier years (Polzin and Chu 2014).

The United States does not collect comprehensive VMT data annually, so we compare the VMT data in Figure 1 (which originate from the U.S. Department of Transportation Federal Highway Administration [FHWA]) with VMT from other sources. The FHWA data derive from estimated state-level VMT by road and vehicle type, which are estimated based on traffic flows on a sample of roads. Figure 2 compares data from FHWA with estimates from the EIA and data from the National Household Travel Survey (NHTS). The EIA estimates are the first year of data reported in each Annual Energy Outlook and derive from a computational model linking household VMT to fuel prices, income, and other factors. The NHTS data derive from a household travel survey that the Department of Transportation has conducted every five to eight years. ${ }^{4}$ The estimated national VMT in Figure 2 is computed based on each survey respondent's estimated total miles driven for all vehicles belonging to the household. NHTS provides estimates for 1995, 2001, and 2009, whereas FHWA and EIA report annual estimates for 1995 through 2013.

The three estimates of national VMT indicate a slowdown in VMT growth sometime in the 2000s. National VMT increased between 1995 and 2001 and grew at a slower rate between

3. More specifically, before 2000, the correlation between annual changes in VMT per driver and annual changes in income was 0.45 , and the correlation between annual changes in VMT per driver and annual changes in employment was 0.40 . After 2000 , these correlations were 0.06 and -0.05 , respectively.

4. Before 2001, the survey was referred to as the Nationwide Personal Transportation Survey. 
Figure 2: Comparison of National VMT Growth, 1995-2013

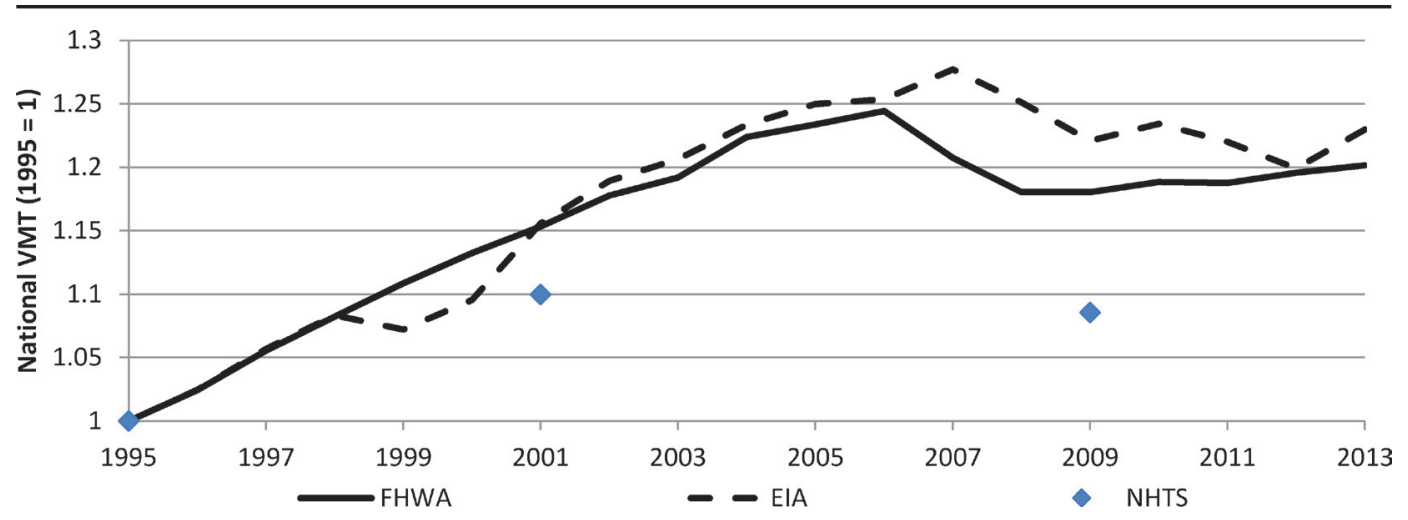

Notes: The figure reports the total VMT by passenger vehicles, with VMT normalized to one in 1995. Each data point for the Energy Information Administration (EIA) series is the first year of data reported in Appendix Table A7 for the Annual Energy Outlook reference case. The Federal Highway Administration (FHWA) series is from the VM-1 publication. The National Household Travel Survey (NHTS) series is from Summary of Travel Trends (FHWA 2011).

2001 and 2009 than between 1995 and 2001. There are some differences among the three sources, however. The EIA and FHWA estimates suggest that VMT peaked in the mid-2000s, decreased until around 2010, and began increasing in the 2010s. The NHTS indicates that national VMT decreased between 2001 and 2009, whereas FHWA and EIA indicate that VMT increased between these two years. Moreover, FHWA and EIA disagree about the year in which VMT peaked (2006 according to FHWA and 2007 according to EIA) and about the year in which VMT started growing again (2008 according to FHWA and 2012 according to EIA). Overall, however, the different sources consistently show that VMT growth began to slow around 2000. ${ }^{5}$ These developments represent a stark contrast to the VMT growth before 2000.

\subsection{Explanations from the Literature}

As discussed in the introduction, we distinguish between two influences on VMT growth: (a) demographics and economic characteristics; and (b) household driving habits, conditional on demographics and economic characteristics. Here, we review the literature on the determinants of VMT. Litman (2013) documents the relationship between economic factors and VMT, showing that low fuel prices, high income, and high employment are associated with high VMT. The slowdown of VMT growth in the 2000s is consistent with recent macroeconomic trends, including a fall in median income for households from 2001 to 2007 and a sharp decline in employment in 2009 that persisted for several years (CEA 2014). The slowdown is also consistent with rising gasoline prices in the mid-2000s and the overall increase in traffic congestion. However, the literature has not considered specifically whether economic characteristics, particularly income and employment, fully explain the path of VMT after 2000.

Several recent studies have considered the role of aging and urbanization in explaining the recent VMT developments. The elderly typically drive fewer miles than young adults, and individuals in urban areas typically drive fewer miles than individuals in rural areas. The share of elderly

5. According to the FHWA data, VMT grew 2.4 percent annually between 1995 and 2001 and by 0.3 percent annually between 2001 and 2009. According to EIA estimates, annual VMT growth declined from 2.4 percent to 0.7 percent, and according to NHTS data, annual VMT growth declined from 1.6 to -0.2 percent over the same time periods. 
in the population has increased as the baby boom generation has aged, ${ }^{6}$ and urbanization rates have been increasing, either of which could have reduced average VMT per household (Davis et al. 2012; Baxandall 2013; Blumenberg et al. 2012).

Regarding the second class of explanations for the declining VMT growth rate, recent studies have focused on the possibility that young adults in the 2000s drove fewer miles than did previous generations of young adults. According to the 2009 NTHS, commuting accounts for about 19 percent of miles traveled (not including work-related business trips), and shopping accounts for about 14 percent of miles traveled. A change in household driving habits among younger age groups could be explained by cultural shifts in commuting patterns, including a stronger preference for public transit and for virtual connectivity for working and socializing (Choo et al. 2005; Mans et al. 2012; McDonald 2015; Brown et al. 2016). In addition, the media have suggested that the growth of internet shopping may have reduced shopping trips, ${ }^{7}$ although Zhou and Wang (2014) and Zhai et al. (2017) do not find strong evidence supporting this hypothesis.

Overall, the literature has not explained the factors underlying the dynamics of VMT shown in Figures 1 and 2. For example, the relationship between VMT and average income may have changed because of changes in driving habits by income group or because of changes in the income distribution. That is, individuals belonging to certain income groups may have started driving less in the 2000s than did individuals belonging to the same income groups in prior years, representing a habitual change. Alternatively, household-level income may have a nonlinear effect on VMT per household. If VMT is a concave function of income, a mean preserving spread of the income distribution (i.e., an increase in variance, holding the mean fixed, which corresponds to an increase in income inequality) could reduce average VMT. In that case, an increase in the share of low-income households after 2000 may have caused the decrease in VMT, representing a situation in which changes in economic characteristics, rather than driving habits, caused VMT to decrease in the 2000s.

In short, the literature has identified several possible explanations for the patterns depicted in Figures 1 and 2. A few studies have provided evidence of changes in demographics, economic characteristics, and driving habits. However, the literature has not evaluated the relative importance of these changes, nor has it distinguished between the possibilities of nonlinear relationships among variables and changes in habits. In the next two sections of the paper, we quantify the contributions of demographics and economic characteristics to VMT, allowing for nonlinear relationships among the variables.

\section{DATA AND METHODOLOGY}

\subsection{Data}

Our analysis combines the Current Population Survey (CPS) and NHTS. The CPS provides accurate annual estimates of demographics. The NHTS links household driving to demographics and economic characteristics during specific survey years. As we explain in this subsection and the next, we combine the data sets to take advantage of their relative strengths.

From the CPS, we compute counts of households by year, household income category, and demographic category from 1995 through 2015. We begin by assigning each household in the

6. The baby boom generation is commonly defined as comprising individuals born between 1945 and 1964 .

7. http://business.time.com/2012/04/13/off-the-road-8-reasons-why-were-driving-less; http://www.slate.com/blogs/money box/2012/03/04/is_e_commerce_ending_driving_html 
March CPS to a unique income and demographic category. For consistency with the 1995 NHTS, we convert nominal income reported in the CPS to 1995 dollars using the consumer price index from the Bureau of Labor Statistics, and we define household income categories by $\$ 5,000$ intervals ( 0 to $\$ 5,000 ; \$ 5,000$ to $\$ 10,000$; and so on), top-coded at $\$ 80,000$. Demographics include age category of the household head, census division, urbanization status, number of workers in the household, household size, education category, and race. We use five-year age categories, and we define education and race categories identically to the 1995 NHTS categories. Education categories are less than high school degree, high school degree, some college, college, and postcollege; race categories are white, black, and other. The household counts are computed using the CPS household sampling weights.

Figure 3 provides summary information from the CPS data, focusing on variation over time in age, income, and number of workers per household. Panel A shows that between 1995 and 2009, the share of households with a household head aged 31 through 45 declined, and the share of households with a household head of age 45 through 60 increased. The share of households with a household head aged above 60 decreased until the early 2000s and then increased. These patterns are consistent with the aging of the baby boom generation.

Panel B shows the dynamics of the income distribution between 1995 and 2009, particularly the fact that income has not risen uniformly across income categories. The share of low-income households (defined as having an income below \$35,000 in 1995 dollars) decreased in the late 1990s and then remained flat. The share of middle-income households (between $\$ 35,000$ and $\$ 70,000$ ) decreased gradually over the period, and the share of high-income households (above $\$ 70,000$ ) increased, particularly in the late 1990s and early 2000s. Thus, the data indicate an overall decrease in the shares of low- and middle-income households and an increase in the share of high-income households.

Panel C shows changes in the shares of households with zero, one, or more than one worker. The share of households with more than one worker was steady in the 1990s and declined in the 2000s, and it was offset by an increase in the share of one-worker households through most of the 1990s and 2000s.

The NHTS data set contains households from the 1995, 2001, and 2009 survey waves. For each household, we compute the total VMT across its vehicles and construct the same income and demographic categories as those in the CPS data set. The appendixes explain how we handle missing income data and how we assign households income categories based on their real income. The NHTS includes a few variables that may be correlated with household VMT but are not in the CPS - particularly the number of licensed drivers, the size of the metropolitan statistical area (MSA), and the number of vehicles belonging to the household. The coding of the MSA size and race variables varies across NHTS waves, and we harmonize the coding across waves.

Panels D through F in Figure 3 report information from the three NHTS waves for comparison with the CPS data in Panels A through C. Panels A and D show that the share of households by broad age category follows similar patterns in the two data sets, although there is a difference for the youngest age category. This difference could reflect sampling variation or the fact that we use the survey respondent to define the age category for NHTS households, whereas we use the household head for CPS households.

Panel E shows shares of NHTS households by income category, and we observe differences between the NHTS data and the CPS data reported in Panel B. According to the NHTS data, the share of low-income households increased from 1995 through 2009, whereas according to the CPS data, the share of low-income households decreased between 1995 and 2001, and then increased. 
Figure 3: Age, Income, and Worker Count Shares, 1995-2009
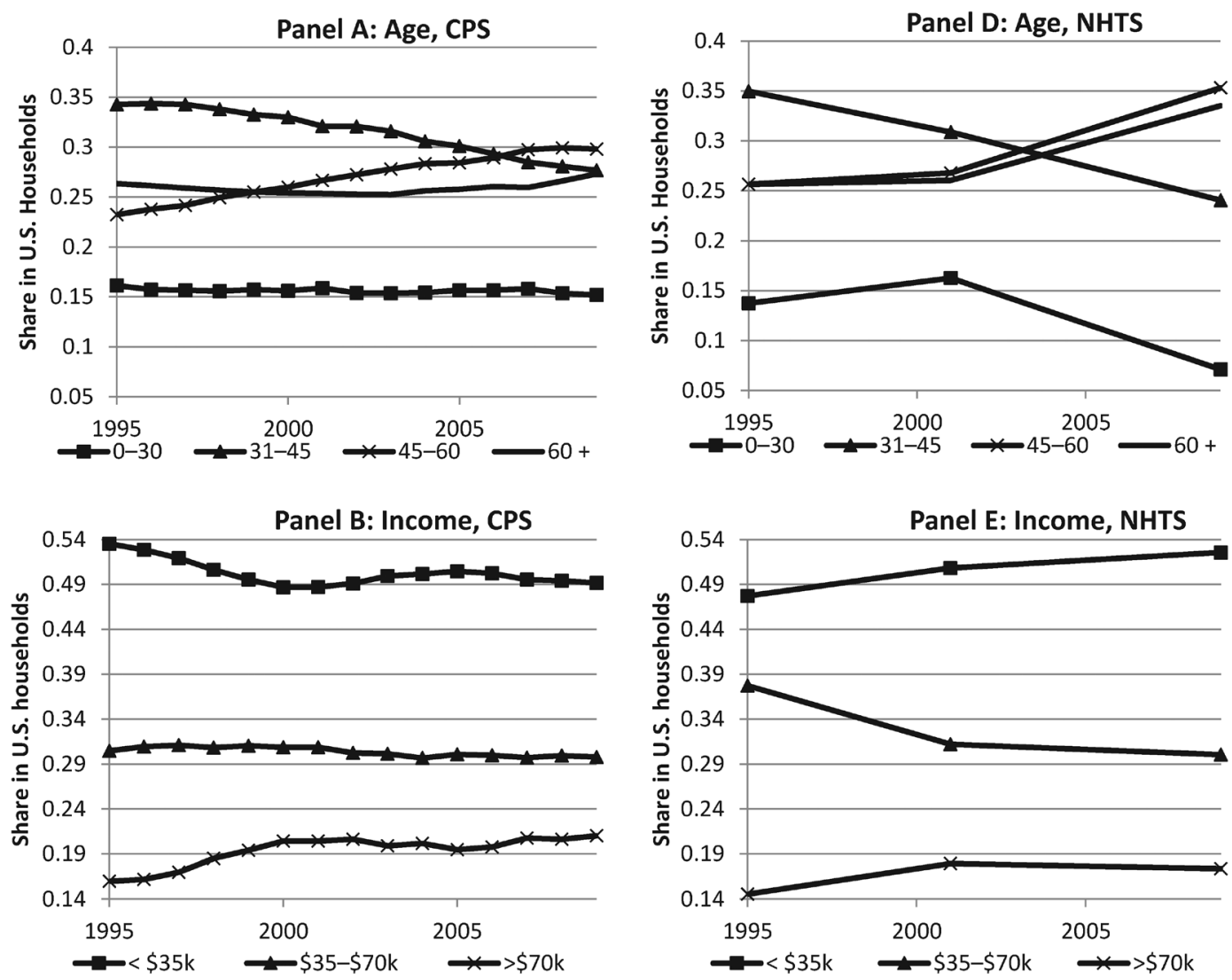

Panel C: Number of Workers in

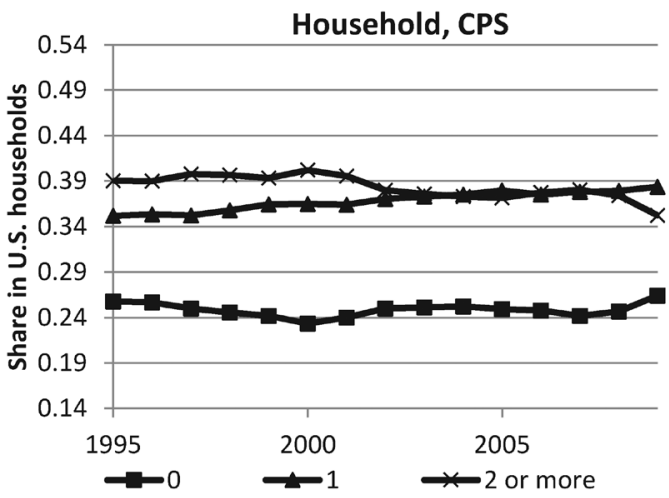

Panel F: Number of Workers in

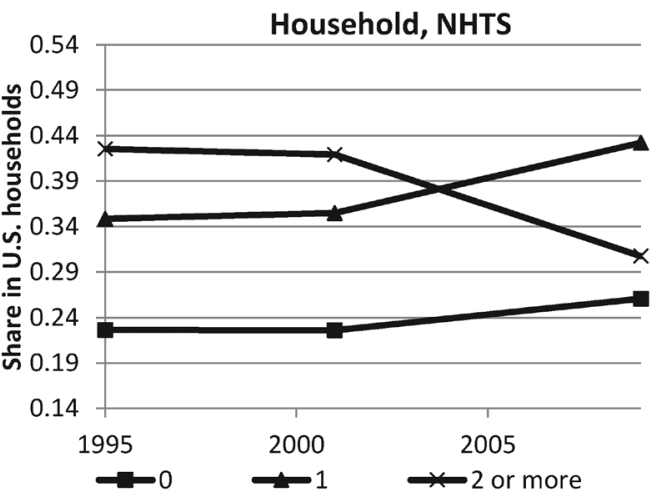

Notes: Panels A and D report shares of the indicated age categories in the total number of U.S. households, Panels B and E report income shares based on income in 1995 dollars, and Panels C and F report shares of households with the indicated numbers of workers. Data in Panels A through C are from the Current Population Survey (CPS), and data in Panels D through $\mathrm{F}$ are from the NHTS.

This difference could arise from sampling variation, as with the age data, but it may also reflect the measurement error in the NHTS introduced by the income imputations discussed above. Because of the NHTS's measurement error and its focus on travel, versus the CPS's focus on labor market 
Table 1: Percentage of Households, by Demographic Category and NHTS Year

\begin{tabular}{|c|c|c|c|c|c|}
\hline & $\begin{array}{c}(1) \\
1995\end{array}$ & $\begin{array}{c}(2) \\
2001\end{array}$ & $\begin{array}{c}(3) \\
2009\end{array}$ & $\begin{array}{c}(4) \\
\text { Change (3)-(1) }\end{array}$ & $\begin{array}{c}(5) \\
P \text {-value }\end{array}$ \\
\hline Number of households & 34,314 & 59,145 & 144,417 & & \\
\hline \multicolumn{6}{|l|}{ Census division } \\
\hline New England & 3.8 & 3.8 & 5.0 & 1.2 & 0.00 \\
\hline Middle Atlantic & 16.0 & 14.7 & 13.5 & -2.5 & 0.00 \\
\hline East North Central & 18.1 & 17.6 & 15.9 & -2.3 & 0.00 \\
\hline West North Central & 7.3 & 6.7 & 7.3 & 0.0 & 0.99 \\
\hline South Atlantic & 19.0 & 20.2 & 19.8 & 0.8 & 0.05 \\
\hline East South Central & 5.6 & 6.2 & 6.3 & 0.7 & 0.01 \\
\hline West South Central & 11.1 & 10.5 & 11.1 & 0.0 & 0.94 \\
\hline Mountain & 3.0 & 4.1 & 7.0 & 4.0 & 0.00 \\
\hline Pacific & 16.0 & 16.2 & 14.2 & -1.8 & 0.00 \\
\hline \multicolumn{6}{|l|}{ MSA size (population) } \\
\hline$<250 \mathrm{k}$ & 7.4 & 6.8 & 7.1 & -0.3 & 0.27 \\
\hline $250-500 \mathrm{k}$ & 7.1 & 8.3 & 8.6 & 1.6 & 0.00 \\
\hline $500 \mathrm{k}-1$ million & 8.1 & 7.8 & 7.7 & -0.4 & 0.15 \\
\hline 1-3 million & 18.6 & 22.3 & 22.0 & 3.4 & 0.00 \\
\hline$>3$ million & 40.4 & 37.0 & 34.9 & -5.5 & 0.00 \\
\hline Not in MSA & 18.3 & 17.8 & 19.6 & 1.3 & 0.01 \\
\hline In urban area & 65.4 & 80.0 & 77.2 & 11.8 & 0.00 \\
\hline \multicolumn{6}{|l|}{ Number of drivers } \\
\hline 0 & 6.0 & 5.4 & 4.7 & -1.3 & 0.00 \\
\hline 1 & 30.4 & 32.6 & 34.0 & 3.7 & 0.00 \\
\hline 2 & 50.6 & 48.7 & 47.9 & -2.6 & 0.00 \\
\hline 3 & 10.2 & 10.2 & 10.2 & 0.0 & 0.92 \\
\hline 4 or more & 2.9 & 3.2 & 3.3 & 0.3 & 0.09 \\
\hline \multicolumn{6}{|l|}{ Number of vehicles } \\
\hline 0 & 9.1 & 8.4 & 8.7 & -0.4 & 0.26 \\
\hline 1 & 29.9 & 31.4 & 31.9 & 2.0 & 0.00 \\
\hline 2 & 41.4 & 37.1 & 36.6 & -4.8 & 0.00 \\
\hline 3 & 14.4 & 14.9 & 14.5 & 0.1 & 0.83 \\
\hline 4 or more & 5.2 & 8.2 & 8.4 & 3.2 & 0.00 \\
\hline
\end{tabular}

Notes: The table reports percentages of households in the indicated demographic category using data from the 1995, 2001, and 2009 NHTS waves. Column 4 reports the percentage point change between the 2009 and 1995 waves, and column 5 reports the $P$-value on the test for equality of the 1995 and 2009 means.

outcomes and income and its extensive use in the literature for estimating income distributions, we consider the CPS income data to be the more reliable.

Table 1 shows changes in demographics across the NHTS survey waves. The data indicate large shifts in some of the demographics, such as a doubling of the percentage of households in the Mountain census division and an 18 percent increase in the urbanization rate; most of these changes are statistically significant. We also observe a shift from two-worker to one-worker households, which reflects macroeconomic conditions and the retiring of the baby boom generation from the workforce. Table 2 shows substantial changes in driving across the survey waves by demographic groups.

\subsection{Methodology}

Much prior research has used aggregated data to link VMT with demographics and economic characteristics (e.g., Small and Van Dender 2007). Typically, these studies estimate an equation of the form

$$
V_{t}=\delta_{1} Y_{t}+\delta_{2} P_{t}+\varepsilon_{t}
$$


Table 2: Average VMT, by Demographic and Income Category and NHTS Year

\begin{tabular}{|c|c|c|c|c|}
\hline & 1995 & 2001 & 2009 & Change (2009-1995) \\
\hline \multicolumn{5}{|l|}{ Age group } \\
\hline $0-30$ & 22,527 & 24,086 & 22,831 & 304 \\
\hline $31-45$ & 23,379 & 25,543 & 24,964 & 1,585 \\
\hline $46-60$ & 23,405 & 24,471 & 24,059 & 654 \\
\hline $61+$ & 11,925 & 12,403 & 14,230 & 2,304 \\
\hline \multicolumn{5}{|l|}{ Income group } \\
\hline$<\$ 35 \mathrm{k}$ & 14,162 & 15,149 & 14,545 & 383 \\
\hline$\$ 35 \mathrm{k}-\$ 70 \mathrm{k}$ & 24,370 & 26,559 & 26,844 & 2,474 \\
\hline$>\$ 70 \mathrm{k}$ & 30,097 & 31,218 & 29,817 & -280 \\
\hline \multicolumn{5}{|c|}{ Number of workers } \\
\hline 0 & 8,924 & 9,515 & 10,325 & 1,401 \\
\hline 1 & 17,695 & 17,801 & 19,249 & 1,555 \\
\hline 2 or more & 28,565 & 31,315 & 32,180 & 3,615 \\
\hline
\end{tabular}

Notes: The table reports the weighted mean VMT of households in the indicated demographic category using data from the 1995, 2001, and 2009 NHTS waves, using household survey weights. The rightmost column reports the percentage point change between the 2009 and 1995 waves.

where $V_{t}$ is national VMT in year $t, Y_{t}$ is income, $P_{t}$ is the gasoline price, $\varepsilon_{t}$ is an error term, and the $\delta$ s are coefficients to be estimated (the equation could include other controls, such as a time trend, which we omit for exposition). The equation may be estimated at the national or subnational level (e.g., by state, as in Baxandall 2013), including variables in levels or logs. Some studies use the average fuel costs per mile of driving instead of the fuel price to account for the effect of fuel economy on driving costs.

Equation (1) assumes that higher moments of the variables do not affect VMT. In that case, two possibilities could explain the change in the relationship between average VMT and average income that occurred after 2000: (a) the coefficients in equation (1) have changed; or (b) equation (1) is misspecified. For example, the income coefficient in equation (1) may have changed after 2000 , or a mean preserving spread of income, combined with a nonlinear relationship between a household's income and its VMT, could change the relationship between average income and national VMT. Given available aggregated data, it would be challenging to distinguish between these two possibilities. For example, the square of income may be highly correlated with income, making it difficult to separately identify the effects of income and its square on national VMT. In addition, omitted variables may bias estimates of equation (1), such as global macroeconomic conditions, which could be correlated with driving habits as well as income and fuel prices.

As we show below, because of these issues, using aggregated data incorrectly attributes the slowdown in VMT growth to changes in habits. Because of these issues with using aggregated data, we adapt an Oaxaca-Blinder decomposition using household-level data from the NHTS and CPS. National VMT is the product of VMT per household and the number of households, and in this analysis we focus on VMT per household. We decompose temporal changes in VMT per household into two classes: (a) the contributions of variables explaining VMT per household; and (b) the contribution of changes in the coefficients on those explanatory variables. This method, which was first applied by Oaxaca (1973) and Blinder (1973) to quantify wage discrimination in labor markets, is an intuitive tool for decomposing the sources of changes in a variable, such as VMT, over time. To the best of our knowledge, our analysis is the first to adopt the Oaxaca-Blinder methodology for examining the relationships among national VMT and demographics, economic characteristics, and driving habits at the household level (CEA 2015 reports our results using an earlier version of this methodology). The standard Oaxaca-Blinder decomposition approach has been used in other envi- 
ronmental and energy contexts, such as for household energy efficiency (Levinson 2014) and energy efficiency in service establishments (Morikawa 2012).

The decomposition in this paper differs from a standard Oaxaca-Blinder decomposition in that we use one data set, the NHTS, to estimate the relationships among VMT per household, demographics, and economic characteristics, and a second data set, the CPS, to measure changes in demographics and economic characteristics over time. Alternatively, we could use only the NHTS data, but using both data sets takes advantage of their relative strengths. The strength of the NHTS data is that they include household-level VMT as well as economic and demographic factors that are highly correlated with VMT per household. The strength of the CPS is the ability to estimate counts of households for each year between 1995 and 2015, which enables a comparison of annual national VMT estimates with the level of VMT predicted by changes in demographics and economic characteristics (recall that the NHTS data are available only for 1995, 2001, and 2009). A further strength of the CPS is the lower measurement error of income, relative to the NHTS.

More specifically, we generalize equation (1) to include a broader set of explanatory variables:

$$
V_{t}=\gamma_{t} \mathbf{C}_{t}+\eta_{t}
$$

We model VMT in a semiparametric manner by assigning an average VMT for each household group. The bolded terms $\boldsymbol{\gamma}_{t}$ and $\mathbf{C}_{t}$ denote vectors, and each element of both vectors represents a household group. In the main analysis, groups are defined based on income, number of workers, and age group. For example, one group includes households with income between $\$ 50,000$ and $\$ 55,000$, with one worker and with a household head aged 35 to 39. There are a total of 272 groups. The vector $\gamma_{t}$ represents the average driving of households in each group in year $t$ and $\mathbf{C}_{t}$ contains the number of households in year $t$ belonging to each group. The final term, $\eta_{t}$, represents idiosyncratic differences in driving that are not explained by household group driving habits. Taking the expectation of this equation, we have

$$
E\left[V_{t}\right]=\gamma_{t} \mathbf{C}_{t}
$$

Using this equation, we can express the change in expected national VMT between years 0 and $t$ as

$$
E\left[V_{t}-V_{0}\right]=\gamma_{0}\left(\mathbf{C}_{t}-\mathbf{C}_{0}\right)+\left(\boldsymbol{\gamma}_{t}-\boldsymbol{\gamma}_{0}\right) \mathbf{C}_{t}
$$

We compute the decomposition with

$$
V_{t}-V_{0}=\hat{\gamma}_{0}\left(\mathbf{C}_{t}-\mathbf{C}_{0}\right)+\left(\hat{\gamma}_{t}-\hat{\gamma}_{0}\right) \mathbf{C}_{t}
$$

where the coefficients with hats represent empirical estimates. The two terms in this equation conform precisely to the two classes of potential explanations for the changes in VMT that we defined in the introduction: changes in demographics and economic characteristics as represented by changes in the number of households in each group (i.e., $\mathbf{C}_{t}-\mathbf{C}_{0}$ ), and changes in driving habits, conditional on demographics and economic characteristics, as represented by changes in the coefficients (i.e., $\left.\hat{\gamma}_{t}-\hat{\gamma}_{0}\right)$.

The typical approach to estimating (2) is to use multiple cross sections of data and estimate the relationships between household VMT and demographics and economic characteristics using each cross section of data separately to obtain $\hat{\gamma}_{0}$ and $\hat{\gamma}_{t}$. We are unable to apply this approach for recent years because household-level VMT and characteristics data through 2015 are not available. Therefore, we adopt an alternative approach, and we estimate the two terms in (2), $\hat{\gamma}_{0}\left(\mathbf{C}_{t}-\mathbf{C}_{0}\right)$, 
and $\left(\hat{\gamma}_{t}-\hat{\gamma}_{0}\right) \mathbf{C}_{t}$, in separate steps. To estimate $\hat{\gamma}_{0}\left(\mathbf{C}_{t}-\mathbf{C}_{0}\right)$, we first estimate the household-level equation

$$
V_{h 0}=\boldsymbol{\gamma}_{0} \mathbf{I}_{h 0}+\varepsilon_{h 0}
$$

using 1995 NHTS cross-sectional data, where $\mathbf{I}_{h 0}$ is a vector indicator function such that the corresponding group element is equal to one if household $h$ in year 0 belongs to the group and $\varepsilon_{h 0}$ is a household-specific error term. The groups and coefficients $\gamma_{0}$ have the definitions from above. We estimate equation (3) by weighted least squares using NHTS sample weights, yielding coefficient estimates $\hat{\gamma}_{0}$. Thus, the coefficients represent the weighted average VMT per household across households belonging to the corresponding groups, and we refer to $\hat{\gamma}_{0}$ as the vector of expected group VMT per household in the base year (i.e., 1995). ${ }^{8}$ Importantly, we estimate a separate VMT for each group rather than impose linear relationships between VMT and the explanatory variables. For each year between 1995 and 2015, we multiply the estimated group VMT per household by the count of households in the corresponding group from the CPS to obtain the predicted group VMT. Summing the predicted group $g$ VMT over groups yields the predicted national VMT in year $t$ :

$$
\hat{V}_{t}^{0}=\hat{\gamma}_{0} \mathbf{C}_{t}
$$

The superscript 0 on the left-hand-side term in equation (4) denotes that the prediction is performed using the coefficients estimated from equation (3) and household data from year 0 . Note that predicted national VMT in year $t$ using year $t$ coefficients is equal to observed national VMT in year $t: V_{t}=\hat{V}_{t}=\hat{\gamma}_{t} \mathbf{C}_{t}$. The difference between predicted national VMT in year $t, \hat{V}_{t}^{0}$, and national VMT in year $0, \hat{V}_{0}$, represents the first class of potential explanations for the change in VMT between year 0 and year $t$ - that is, changes in demographics and economic characteristics:

$$
\hat{V}_{t}^{0}-V_{0}=\hat{\gamma}_{0}\left(\mathbf{C}_{t}-\mathbf{C}_{0}\right)
$$

To estimate the second term in equation (2), $\left(\hat{\gamma}_{t}-\hat{\gamma}_{0}\right) \mathbf{C}_{t}$, we first substitute (5) into (2) to obtain

$$
V_{t}-V_{0}=\hat{V}_{t}^{0}-V_{0}+\left(\hat{\gamma}_{t}-\hat{\gamma}_{0}\right) \mathbf{C}_{t}
$$

Canceling like terms and rearranging yields

$$
V_{t}-\hat{V}_{t}^{0}=\left(\hat{\gamma}_{t}-\hat{\gamma}_{0}\right) \mathbf{C}_{t}
$$

We estimate (6) using the difference between observed national VMT in year $t$ and predicted national VMT in year $t$, where the prediction is based on year 0 coefficients. Adding equations (5) and (6) yields equation (2).

Figure 4 shows that equations (5) and (6) are useful for interpreting the results. To simplify the presentation, the horizontal axis is a scalar that summarizes the demographics and economic characteristics in $\mathbf{C}_{t}$. The two sloped lines represent national VMT growth between year 0 and year $t$. The bottom line is the predicted VMT using habits estimated in year 1995, and the top line is the predicted VMT using habits estimated in year $t$ (i.e., 2009 in the figure). The bottom bracketed term on the vertical axis is the change in VMT over time that is explained by changes in household de-

8. Because we weight the household observations by household weights, estimation of equation (3) yields the same coefficient estimates as those estimated if we aggregate VMT by group and estimate the model at the group level. 


\section{Figure 4: Schematic Representation of the Oaxaca-Blinder Decomposition}

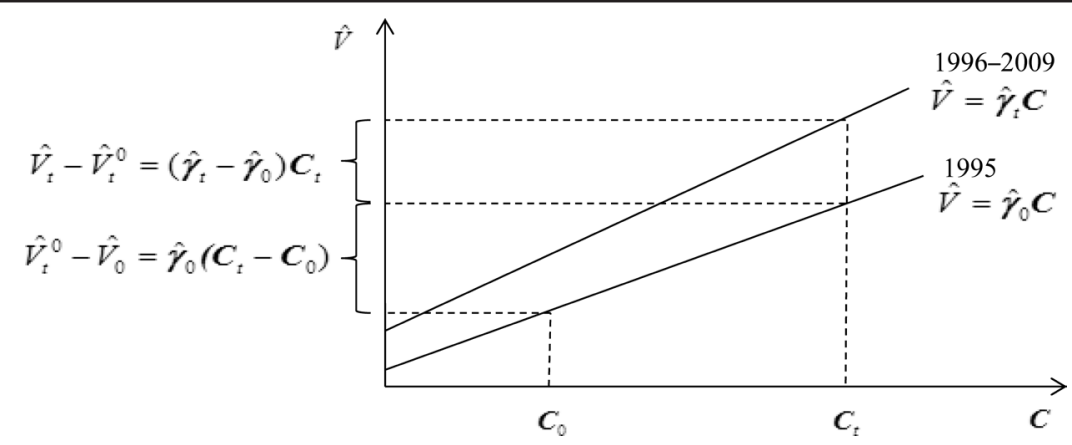

mographics and economic characteristics. The top bracketed term is the change in VMT over time that is explained by changes in habits.

We make several notes about this decomposition. First, if the change in predicted national VMT is similar to the observed change, we conclude that demographics and economic characteristics explain VMT growth. This does not imply that habits do not change over time, but rather that any changes in habits cancel one another out. For example, an increase in driving by low-income households may be offset by a decrease in driving by high-income households.

Second, we do not assign a causal interpretation to the decomposition. Equation (3) likely omits variables that affect VMT and that are correlated with the variables included in equation (3). If the relationships between the omitted variables and the variables that we include in equation (3) do not change over time, we will correctly distinguish between the contribution of demographics and economic characteristics and the contribution of changes in driving habits (i.e., the coefficients on the demographics and economic characteristics). This issue is present in the literature on wage discrimination for which the Oaxaca-Blinder method was first applied, where race or gender may be correlated with variables that are omitted from typical wage equations.

Third, equation (3) does not include gasoline prices. We omit prices from this equation because much of past research using cross sections of household data (e.g., Goldberg 1998; Li et al. 2013) has failed to identify the effect of gasoline prices on VMT, largely because of limited cross-sectional price variation. ${ }^{9}$ In implementing the decomposition, we compute the predicted national VMT for each year according to equation (4). Then, we compute the percentage change in the real gasoline price between year 0 and year $t$. We multiply this percentage change by -0.1 , which is our baseline assumption of the elasticity of VMT with respect to real gasoline prices. This elasticity is comparable to that used by Small and Van Dender (2007), and below we consider alternatives that are based on other estimates in the literature. Additionally, we adjust the national VMT by the percentage change in VMT caused by the change in gasoline price since the base year.

Finally, equation (3) uses income category, number of household workers, and age category in defining the household groups. These variables are chosen for two reasons. The first is that they explain a large share of variation in VMT across households and perform well in predicting household VMT out of sample. ${ }^{10}$ This criterion for selecting variables reduces concerns about overfitting that might otherwise apply to an Oaxaca-Blinder style decomposition. Other studies have used licensed drivers, number of household vehicles, and urbanization status as explanatory variables. Section 4.2 shows that the results are similar if we include them.

9. We reach a similar conclusion using a cross section of NHTS data.

10. For example, using half of the 1995 sample to estimate equation (3) and comparing observation with prediction for the other half of the 1995 sample. 
The second consideration for choosing these variables is that implementing this methodology requires that we define demographic groups such that each group appears in the 1995 NHTS cross section as well as each year from 1995 through 2015 in the CPS data. The typical annual CPS sample size of about 70,000 households prevents us from defining groups that are much more disaggregated or that have additional variables, such as education category, compared with the group definition we use.

Above, we noted our preference for combining the NHTS and CPS data to perform the decomposition. On the other hand, a potential drawback of the CPS is that it does not include certain variables, such as the number of licensed drivers in the household, which are likely to be correlated with VMT. ${ }^{11}$ Given these trade-offs, below we report a complementary set of results that use the NHTS data for equations (3) and (4) and include these additional variables. Because the latter decomposition includes a richer set of explanatory variables, comparing the two sets of results informs the question of whether the limited set of explanatory variables in the former decomposition yields misleading results (note that because we do not interpret the coefficients causally, we are not concerned about including variables that may be endogenous to VMT, such as the number of licensed drivers).

\section{EXPLAINING THE RECENT CHANGES IN VMT GROWTH}

\subsection{CPS Results}

\subsubsection{Main Results}

Figure 5 compares the estimated national VMT from FHWA and NHTS (repeated from Figure 2) with the predicted national VMT based on equations (3) and (4). To predict national VMT, we estimate equation (3) using 1995 NHTS data, yielding estimated VMT per household for each income-worker count-age group. For reference, Appendix Figure 1 reports means of estimated VMT per household by income, worker count group, or age group (the estimated coefficients themselves are hard to interpret, but they are available on request). For each year from 1995 through 2015, the estimated VMT for each group is equal to the estimated VMT per household multiplied by the number of households in the corresponding group computed from the CPS. Predicted national VMT in each year is the sum across groups of estimated VMT by group (equation [4]); Figure 5 plots predicted national VMT for each year from 1995 through 2015. All national estimates are normalized to one in 1995 for comparability. Equation (5) shows that changes in predicted VMT over time correspond to the contribution of changes in demographics and economic characteristics to the change in observed VMT. Equation (6) shows that the difference between observed and predicted VMT corresponds to the effects of changes in driving habits on VMT.

The predicted VMT reproduces the VMT slowdown of the FHWA and NHTS data, even though the two estimates disagree about the magnitude of the slowdown. The predicted VMT growth is similar to the observed VMT growth from FHWA and NHTS. Between 1995 and 2001, predicted annual growth is 2 percent, which is midway between FHWA (2.4 percent) and NHTS (1.6 percent). Between 2001 and 2009, predicted annual growth is 0.2 percent, which is again midway between

11. These variables are examples of those that are omitted from equation (3) and prevent us from interpreting the coefficients in the equation as the causal effects of the independent variables on VMT. However, even if we were to include these variables in equation (3), we would still be concerned about other factors that are omitted from the equation and are not included in the NHTS survey. 
Figure 5: Comparing Estimated and Predicted VMT Growth, CPS

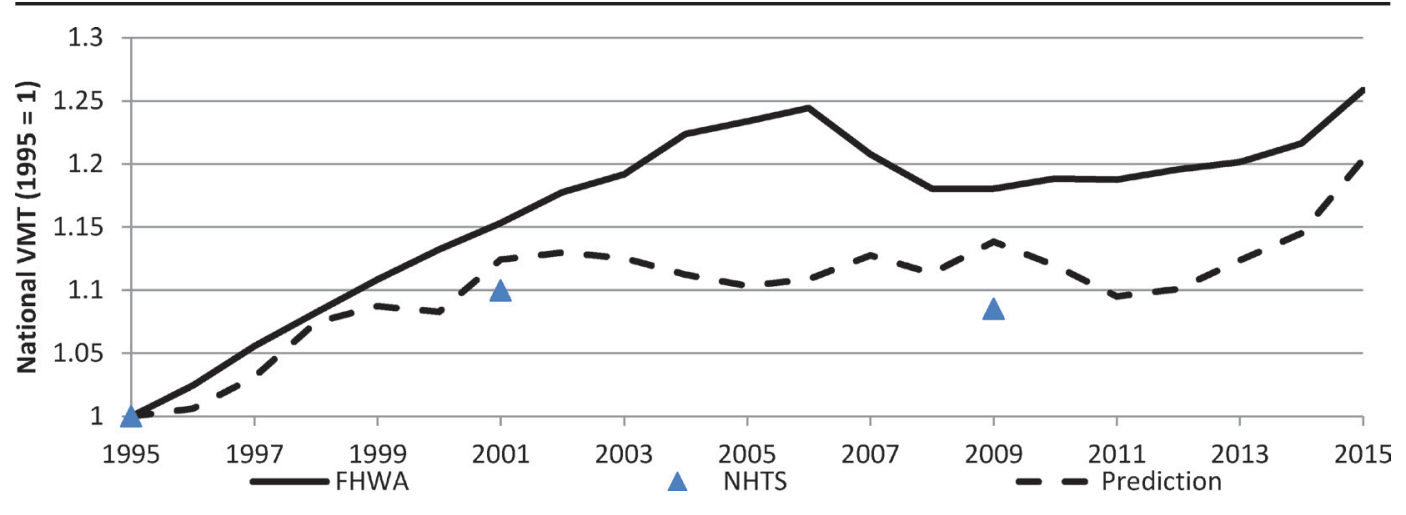

Table 3: Contributions of Income, Age, and Worker Count to Changes in Household VMT, 1995-2015

\begin{tabular}{lcccc}
\hline & $(1)$ & $(2)$ & $(3)$ & $(4)$ \\
& $1995-2000$ & $2000-2005$ & $2005-2010$ & $2010-2015$ \\
\hline Income & 557 & -246 & 30 & -12 \\
Age & -22 & -19 & -52 & -61 \\
Number of workers & 211 & -349 & -293 & 83 \\
Total & 747 & -614 & -315 & 10 \\
\hline
\end{tabular}

Notes: The table reports changes in VMT per household over the five-year intervals indicated in the column headings. Equation (3) is estimated including fixed effects for the variables indicated in the row headings. Each row in the table reports a single counterfactual. For example, the first row of column 1 reports the difference between the predicted VMT using 2000 household income rather than 1995 household income, and holding all other demographic variables fixed at 1995 levels. The other columns report results for the indicated five-year intervals.

FHWA and NHTS. After 2009, predicted and FHWA annual growth are both 1 percent per year. The similarity of the predicted and estimated national VMT growth suggests that demographics and economic characteristics explain the slowdown of VMT growth in the 2000s and the recovery of VMT growth in the 2010s. Although there were changes over time in driving habits for particular groups - for example, among millennials, as we show in Section 4.3 - to a large extent, changes in driving habits among certain groups cancel out changes among other groups; on balance, demographics and economic characteristics explain the VMT dynamics during this period.

We next consider which demographic and economic variables made the largest contribution to changes in VMT. Changes in national VMT depend on changes in the number of households and changes in the VMT per household. To simplify the analysis, we focus on the contributions of economic and demographic variables to VMT per household rather than national VMT (on average, the number of U.S. households increased 1 percent per year between 1995 and 2015).

To address this question, we first estimate equation (3) using fixed effects for the variables indicated in the row headings of Table 3 . The bottom of Table 3 shows the change in average VMT per household predicted using the changes in CPS household counts during the five-year intervals indicated in the column headings. Each of the other rows reports a separate counterfactual. For example, in column 1, the first row reports the difference in predicted VMT per household using the 2000 income distribution rather than the 1995 income distribution. The first row shows that between 1995 and 2000, the change in income distribution increased average VMT per household by 557 miles, which is about 3 percent of the 1995 mean. Between 2000 and 2005, the change in the income distribution reduced VMT by about 246 miles. Appendix Figure 1 shows that VMT per household 
increases steeply with income at low income levels but is largely independent of income at higher income levels. This nonlinear relationship between income and VMT per household explains why income contributed negatively to VMT per household in the early 2000s even though average income increased during this period (see Figure 1).

Table 3 also shows that age contributed negatively to VMT per household, which is consistent with explanations offered in the literature. Average VMT per household is substantially lower for the oldest age group than for the other age groups, which causes average VMT across all households to decrease as the population share of the oldest age group increases over time. However, as Figure 3 shows, the population share of the oldest age group increases by just 2 percentage points between 2000 and 2009, causing the effect of aging on the overall average to be small. Appendix Figure 1 shows that average VMT varies little across the other age groups, implying that changes in the population shares of these groups have little effect on overall average VMT per household. In contrast, Appendix Figure 1 shows considerably greater variation across income and number of worker groups than across age groups. This explains why income and number of workers contribute more than age to the overall changes in average VMT per household.

Changes in the number of workers per household reduced average VMT per household during the 2000s and increased VMT per household in the 2010s; although not shown in the table, the increasing number of households further contributed to the national VMT growth in the 2010s. Thus, the income and number of worker variables appear to be more strongly correlated with changes in VMT per household than is age. Again, we caution against making causal interpretations of these results, and the proper interpretation is that income and number of workers (or omitted variables correlated with them), rather than age, explain changes in national VMT.

\subsubsection{Robustness and Comparison with Alternative Models}

In this subsection, we briefly discuss the robustness of these conclusions to alternative versions of equation (3), referring to Figure 5 as the baseline. Appendix Figure 2 displays the results of several additional decompositions that differ from the baseline projection in Figure 5, as indicated in the figure notes. First, we show that the results are insensitive to using household VMT based on odometer readings rather than self-reported household VMT. The household VMT data used for the baseline are based on the household's reported annual mileage for each vehicle (in cases of missing data, the Department of Transportation imputes the household VMT). By comparing self-reported and odometer-based household VMT, Li et al. (2013) suggest that the self-reported data include measurement error. Households appear to accurately estimate their VMT on average, but there is evidence of compression; low-VMT households overestimate their VMT, and high-VMT households underestimate theirs. If it is correlated with demographics or income, this measurement error could yield misleading inferences about the importance of demographics and income in explaining national VMT growth. To address potential concerns about measurement error in the self-reported household VMT, we replace the self-reported household VMT with a measure of household VMT based on odometer readings in equation (3). Appendix Figure 2 shows that projected national VMT is similar to the baseline if we use odometer-based rather than self-reported household VMT. We prefer to use self-reported rather than odometer-based household VMT as the baseline because the odometer-based household VMT data are missing for a large share of households (in fact, missing values caused the Department of Transportation to discontinue collecting two odometer readings after the 2001 survey).

Second, the variables included in equation (3) as the basis for the decomposition reflect a balancing between the desire to include variables that strongly predict VMT and the need to com- 
bine the CPS and NHTS data. The main conclusions are robust to alternative ways of estimating equation (3) that represent different balances of these considerations. As noted in Section 3.2, we define groups based on income, age, and number of workers to ensure a balanced panel of groups in the CPS data. Basing groups on additional information, such as education, creates an unbalanced panel, causing certain individual age-income-worker count-education groups to appear in the CPS data but not in the NHTS cross section. For such groups, we cannot estimate $\boldsymbol{\gamma}_{0}$ in equation (3). However, as an alternative to the baseline, we can construct groups based on other combinations of demographics and economic variables. For example, Appendix Figure 2 shows the results if we define groups based on income category, number of workers, age category, urbanization status, and household size. In equation (4), we sum over the groups that appear in every year in the CPS data. Therefore, the national estimate is based on a subset of U.S. households, whereas the baseline national estimate is based on all U.S. households. Despite the difference in variable construction and estimation, the results are similar to the baseline.

Third, an alternative approach to adding variables besides income, age, and number of workers to equation (3) is to include the demographic and economic variables independently of one another rather than as interactions. We include as independent variables in equation (3) the fixed effects for income category, age category, and number of workers, as well as fixed effects for other categorical variables: census division, education category, race category, and urbanization status (this represents the largest set of variables that are defined consistently in the NHTS and CPS). Compared with the baseline, this approach allows us to include additional variables in predicting household VMT and does not require a balanced panel of CPS household counts to predict household VMT in each year. Although we prefer the baseline because it allows for interactions among demographic and economic variables and because it facilitates the projections in Section 5, Appendix Figure 2 shows that the results are nearly identical if we use these variables as fixed effects in equation (3).

As a robustness analysis (not reported but available on request), we can perform the decomposition using 2001 or 2009 as the base year, rather than 1995. The conclusions regarding the roles of demographic and economic variables are similar using the alternative base years. This addresses the concern that the Oaxaca-Blinder decomposition is not unique because the calculations depend on the choice of base year. Moreover, Appendix Figure 3 shows that the predicted VMT is similar using alternative elasticities of household VMT to gasoline prices. ${ }^{12}$

Next, we consider whether the semiparametric approach used to estimate equation (4) suitably captures the variation in VMT across households. We assess this question in two ways, first by comparing the observed VMT per household with the VMT per household predicted using subsamples of the 1995 NHTS data. If the approach did not suitably capture the household VMT variation, the predictions would perform poorly out of sample. In Appendix Figure 4, we compare the predicted and observed VMT per household by group, where predictions are made using subsamples of the 1995 NHTS data. Note that by construction, the predictions match observation perfectly if we use the full set of 1995 NTHS data. We report results using randomly selected 90, 75, and 50 percent subsamples. Even in the 50 percent subsample, the predictions match observation closely, as the predictions lie close to the 45-degree line.

12. More specifically, predicted annual VMT growth rates between 1995 and 2001 do not depend on the elasticity because real fuel prices changed only slightly during these years. Between 2001 and 2009, real fuel prices increased and predicted annual VMT growth ranged between 0.3 and 0.7 percent, depending on the elasticity. Between 2009 and 2015 , predicted annual growth was between 0.8 and 1 percent. The larger VMT-price elasticity, of -0.2 , may correspond to a medium or long-run elasticity of VMT to gasoline prices (Gillingham 2014). In that sense, the similarity between the baseline and alternative assumptions in Appendix Figure 3 suggests that the conclusions are robust to allowing for the longer-term responses of VMT to gasoline prices. 
Second, we compare our methodology with alternatives that impose restrictions on the relationships between VMT and the explanatory variables. Appendix Figure 5 plots the predicted against observed VMT per household, where predictions are made using the regression model indicated in the figure notes. In Panel A, we regress household VMT on linear measures of income, age, and number of workers, rather than including the interactions of the category fixed effects. In Panel $\mathrm{B}$, we regress household VMT on fixed effects for income group, age group, and number of workers. The figure shows that these approaches capture much less of the variation in household VMT than does the baseline, which estimates VMT separately for each of the 272 groups. The restrictive approaches considered in Appendix Figure 5 do not yield predictions greater than 40,000, although average VMT is substantially higher than 40,000 for several of the groups. This result demonstrates the problems with using a more restrictive model than the baseline. Moreover, the predictions using the restrictive models are noisier than the predictions using the baseline (compare Appendix Figures 4 and 5). These results suggest that the preferred methodology incorporates a substantial amount of cross-household VMT variation.

Finally, we compare the Oaxaca-Blinder methodology with an alternative in which we estimate an aggregate model, similar to equation (1). Appendix B describes the methodology, which uses data aggregated from the NHTS by state and year for 1995 through 2009. Appendix Figure 6 shows that the aggregate analysis suggests that changes in driving habits explain the slowdown in VMT growth - that is, the opposite conclusion from our baseline results. As we discussed above, the nonlinear relationships between VMT and the explanatory variables explain the dynamics of VMT in the 2000s - that is, changes in the income distribution contributed to the decline in VMT even though average income grew during this period. The aggregate model does not capture such nonlinearities; higher moments of income are too highly correlated with mean income in the aggregated data to identify their effects on VMT. This result underscores the importance of using the Oaxaca-Blinder analysis, which addresses the shortcomings of the aggregate analysis described in Section 3.2.

\subsection{NHTS Results}

As discussed in Section 3.2, we use the CPS household data from 1995 to 2015 for predicting national VMT according to equation (4) partly because of the lower measurement error for income, relative to the NHTS. For comparison with the baseline results, we use NHTS data for equation (4) and show the results in Appendix Figure 7. To fully take advantage of the NHTS data, we first estimate equation (3) including fixed effects for a larger set of variables than we use in the baseline: income category, age category, census division, MSA size category interacted with urbanization status, number of workers, number of drivers, number of vehicles, and population density category. Including these variables improves the fit of equation (3), increasing the $R$-squared from about 0.2 to 0.3 , compared with the baseline in which we include interactions of income category, age category, and number of workers. Despite the differences in the variables used in equation (3) and the differences between NHTS and CPS household counts (see Figures 3 and 4), the overall conclusion is the same as the baseline regarding the contribution of demographics and economic characteristics to VMT dynamics. The figure indicates an increase in predicted national VMT between 1995 and 2001, followed by a decrease in predicted national VMT between 2001 and 2009. The increase in the first time period is less than that using CPS household data in Figure 5, but nonetheless the pattern of predicted VMT over the two periods mirrors the evolution of actual national VMT estimated from the NHTS survey responses. 
Appendix Figure 8 shows that the conclusions using NHTS household data for equation (4) are similar if we take alternative approaches to constructing the variables and estimating equation (3). Section 3.1 discusses the procedure for imputing household income categories based on income in 1995 dollars. For the analysis plotted in Appendix Figure 7, we match NHTS and CPS households based on demographics and income category, and we impute the income of the NHTS household using a randomly selected CPS household belonging to the same cell. As an alternative, we use the mean income of CPS households in the same cell rather than the income of a randomly selected household. In expectation the two imputation methods yield the same imputed income, and Appendix Figure 8 shows that the results are qualitatively similar using the alternative imputation method.

The results using NHTS household counts for equation (4) (i.e., Appendix Figure 7) are qualitatively similar although not identical to the results using CPS counts for equation (4) (i.e., Figure 5). In principle, this difference could be explained by our use of different variables in equation (3) for the two cases or by our inclusion of fixed effects for categorical variables in Appendix Figure 7 versus interactions of categorical variables in Figure 5. However, two additional results shown in Appendix Figure 8 suggest that neither of these explanations is the cause of the differences between Figure 5 and Appendix Figure 7. Specifically, the results are similar to Appendix Figure 7 if we use the NHTS household counts but use only the CPS variables for equations (3) and (4), or if we include interactions of variables rather than fixed effects. Because the latter uses the same variables as the CPS analysis, differences between the CPS and NHTS results are due to differences in sampling methodology of the surveys. Thus, the differences between the CPS and NHTS results appear to be due to differences in sampling methodology and possibly the greater measurement error for the NHTS income data.

\subsection{Revisiting the Millennials and Amazon Hypotheses}

As discussed in Section 2.2, several recent studies and popular media accounts have suggested that changes in driving habits, particularly related to millennials and internet shopping, explain a substantial portion of the slowdown in national VMT growth in the 2000s. Our results, however, suggest that changes in demographics and economic characteristics, rather than household driving habits, explain this slowdown as well as the subsequent increase. In this section, we reconcile our findings with those of other studies and popular media. In Table 4, we compare the average VMT per household of households headed by adults aged 21 to 30 (Panel A) with average VMT per household of households headed by adults aged 31 to 40 (Panel B). The first row of each panel shows the mean VMT per household as reported in the 1995 and 2009 waves of the NHTS. Panel A includes household heads born between 1965 and 1974 in the first column and household heads born between 1979 and 1988 in the second column; the latter group corresponds roughly to millennials. The first row of Panel A shows that younger (i.e., aged 21 to 30) households drove about 3.5 percent less in 2009 than did younger households in 1995. The next two rows show that after controlling for income and other demographics, younger households in 2009 drove about 11.5 percent less than did younger households in 1995; this estimate is similar to that in Blumenberg et al. (2012). By comparison, Panel B shows that after controlling for income and demographics, older households (i.e., aged 31 to 40) drove 4.1 percent less in 2009 than did older households in 1995. Thus, we observe a decrease in demographic and income-adjusted household VMT between 1995 and 2009 for both age categories, but a larger decrease for the younger group than for the older group.

This pattern is consistent with claims that millennials drive less than did earlier cohorts. However, the results of the decomposition in Figure 5 suggest that the apparent change in driving habits of young adults is not large enough to be the major factor explaining changes in VMT growth 
Table 4: Changes in Household VMT by Age Group, 1995-2009

Panel A: Household head is $21-30$ years old

\begin{tabular}{lccc}
\hline & & Percentage difference between \\
& 1995 & 2009 & 2009 and 1995 \\
\hline Mean VMT per household & 22,717 & 21,950 & -3.50 \\
Control for income and number of workers & 22,329 & 21,817 & -2.35 \\
Add other demographics & 22,606 & 20,284 & -11.45 \\
\hline
\end{tabular}

Panel B: Household head is $31-40$ years old

\begin{tabular}{lccc}
\hline & & Percentage difference between \\
& 1995 & 2009 & 2009 and 1995 \\
\hline Mean VMT per household & 22,841 & 23,950 & 4.63 \\
Control for income and number of workers & 20,483 & 21,026 & 2.58 \\
Add other demographics & 19,980 & 19,188 & -4.12 \\
\hline
\end{tabular}

Notes: Panel A reports VMT per household for households with respondents aged 21-30, and Panel B includes households with respondents aged 31-40. The first column includes households in the 1995 NHTS wave, and the second column includes households in the 2009 NHTS wave. The first row in both panels reports the weighted mean of VMT per household using NHTS survey weights. The second row reports the predicted mean household VMT after controlling for income category and the number of workers. The third row also includes household size, urbanization status, census division, education category, and race category.

Table 5: Daily Shopping Trips by Age and Income Groups

\begin{tabular}{|c|c|c|c|c|c|c|}
\hline & (1) & (2) & (3) & (4) & (5) & (6) \\
\hline & \multicolumn{3}{|c|}{ Daily VMT for shopping trips } & \multicolumn{3}{|c|}{ Share of shopping trips in daily VMT } \\
\hline & 1995 & 2001 & 2009 & 1995 & 2001 & 2009 \\
\hline \multicolumn{7}{|c|}{ Panel A: Age } \\
\hline $0-30$ & 9.5 & 12.7 & 11.6 & 0.142 & 0.168 & 0.178 \\
\hline $31-45$ & 11.8 & 13.2 & 10.4 & 0.156 & 0.168 & 0.165 \\
\hline $46-60$ & 12.8 & 14.6 & 12.1 & 0.165 & 0.195 & 0.189 \\
\hline $61+$ & 11.3 & 11.6 & 11.3 & 0.243 & 0.286 & 0.253 \\
\hline \multicolumn{7}{|c|}{ Panel B: Income } \\
\hline$<\$ 35 \mathrm{k}$ & 10.0 & 12.0 & 11.0 & 0.190 & 0.218 & 0.231 \\
\hline$\$ 35 \mathrm{k}-\$ 70 \mathrm{k}$ & 11.7 & 14.7 & 11.3 & 0.163 & 0.191 & 0.177 \\
\hline$>\$ 70 \mathrm{k}$ & 14.8 & 14.5 & 11.8 & 0.159 & 0.172 & 0.162 \\
\hline
\end{tabular}

Notes: The table reports daily VMT for shopping trips in columns 1-3 and the share of shopping trips in total daily VMT in columns 4-6. For each household, total daily VMT is computed from the household's trip diaries. Shopping VMT is computed using trips for which the reported purpose is shopping. Each column reports the mean shopping VMT and share of shopping VMT in total daily VMT for the NHTS wave indicated in the column heading and for the age group (Panel A) or income group (Panel B) indicated in the row heading. All cells report weighted averages using NHTS trip weights.

since 2000. That is, millennials account for just 15 percent of national VMT, and the change in their habits corresponds to a 1 percent change in national VMT. Nonetheless, it remains possible that changes in driving habits of different age-based groups of households could grow in importance if future cohorts of young adults drive less than earlier cohorts, and if aging millennials continue to drive less than have earlier cohorts.

Turning to the Amazon hypothesis, in Table 5, we compare daily VMT for shopping trips (columns 1-3) and share of shopping trips in daily VMT (columns 4-6), computed using the NHTS trip diaries. The different columns represent the 1995, 2001, and 2009 waves of the NHTS. Panel A reports results by age group and Panel B by income group. Panel A shows that daily VMT for shopping trips has decreased between 2001 and 2009 for all age groups, especially the middle-aged groups. The share of shopping trips in daily VMT displays a similar but less pronounced trend, 
except for the increase in the share for the youngest age group. Panel B shows that daily VMT for shopping trips has decreased between 2001 and 2009 for all income groups, especially the upper two income groups, and that the share of shopping trips in daily VMT displays a similar but less pronounced trend.

These results are consistent with the hypothesis that shopping trips have decreased and suggest that online shopping could have played a role in this decrease, although the available data do not allow us to assess whether there is a direct link between shopping trips and online shopping. Regardless, the magnitude of this decrease is not sufficiently large to explain the overall trends in VMT (recall that shopping accounts for 14 percent of VMT per household). Consistent with this finding, DOT (2015) reports that although online shopping has increased rapidly, it did not significantly substitute for traditional shopping trips in 2009. As with millennials, however, the change in shopping habits could grow in importance over time.

\section{IMPLICATIONS FOR FUTURE VMT GROWTH}

Having shown that demographics and economic characteristics, rather than driving habits, explain the changes in VMT growth since 1995, in this section we quantify the implications of this finding for future VMT growth. Specifically, we predict VMT growth between 2015 and 2025 under the assumptions that the driving habits of individual groups do not change and that the correlations among the variables used to predict VMT and unobservables do not change. If the latter assumption holds, the prediction is unbiased.

Because this prediction requires counts of households by group in equation (4), and we are not aware of projections of household counts by group, we take three steps that incorporate a reduced-form model of the dynamics of demographics and economic characteristics. First, we assume that the past trend in number of household members per household continues through 2025. Using CPS estimates of the total U.S. population and number of households from 1980 through 2015, we fit a linear time trend to the average number of households per person (i.e., the reciprocal of the number of people per household). We extrapolate this trend through 2025 and multiply the predicted number of households per person by annual Census Bureau estimates of the U.S. population. This calculation yields the predicted number of U.S. households for each year between 2015 and 2025.

In the second step, we predict the number of U.S. households in each income-age-worker count group from equation (4). We calculate the share of households by group and year in the CPS from 1980 through 2015. We fit a linear trend for each group and extrapolate the group-specific trends through 2025, renormalizing the predicted shares to sum to one in each year. Multiplying these predicted group shares by the predicted number of U.S. households from the first step yields the predicted number of households by group and year from 2015 through 2025 .

Third, we predict national VMT through 2025 using equation (4), the household counts from the second step, and the baseline estimates of group VMT (i.e., the estimates used for the baseline decomposition in Figure 5). As with the earlier analysis, we adjust national VMT using EIA projected gasoline prices. Figure 6 plots the results, along with the EIA (2015) projection of national VMT. Our projections imply annual growth of about 0.9 percent per year between 2015 and 2025, versus 1.4 percent growth projected by EIA.

The results are similar if we use the 2009 NHTS rather than the 1995 NHTS to estimate equation (3), which accounts for possible changes in driving habits between 1995 and 2009, such as the changes for young adults discussed in Section 4.3. The similarity of the results using 1995 or 
Figure 6: Comparison of EIA and CPS-Based Projections

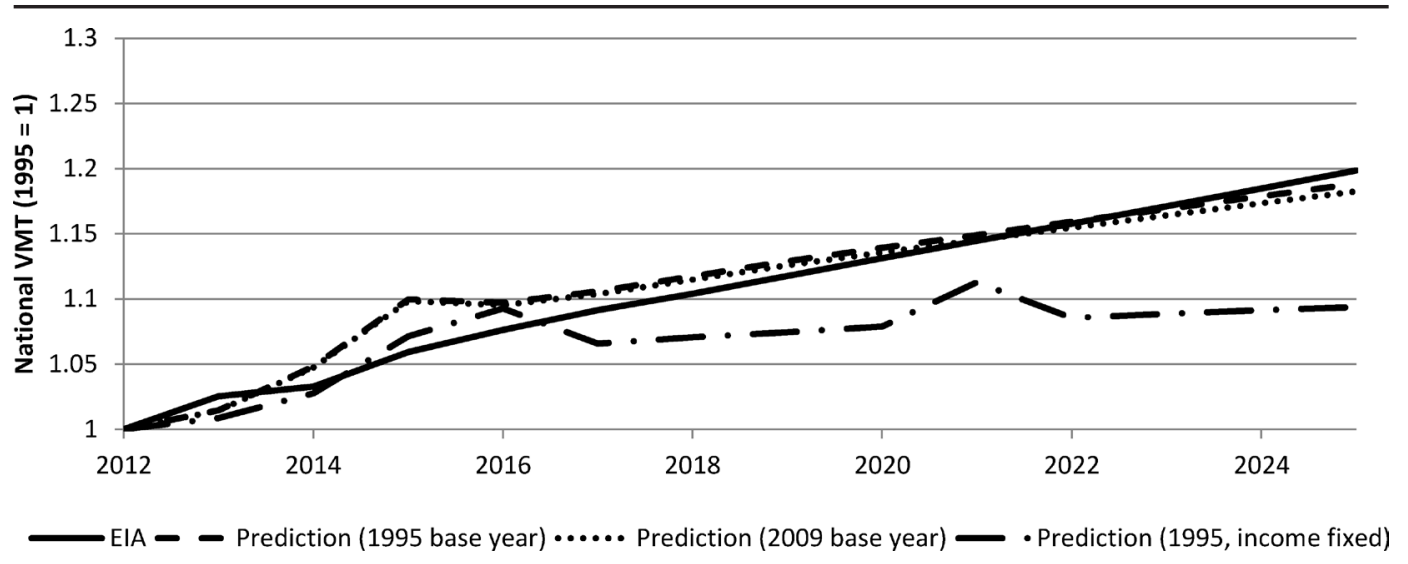

2009 NHTS data confirms the conclusion from Section 4 about the importance of demographics and economic characteristics in explaining recent VMT growth, relative to driving habits.

The prediction of national VMT between 2015 and 2025 depends on changes in the share of households by income category, age category, and number of workers. The final series plotted in Figure 6 shows that income plays a dominant role in the estimated national VMT growth during this ten-year period. If we assume that the income distribution does not change between 2015 and 2025 and that there is no income growth, predicted national VMT would be roughly flat during this period.

\section{CONCLUSIONS}

The transportation sector is a major contributor to oil consumption and emissions. Continued public concerns about U.S. energy security, greenhouse gas emissions, and local air quality have generated popular and academic interest in understanding the recent dynamics of VMT. Because current vehicle emissions and renewable fuel standards determine the long-run vehicle emissions rates and carbon content of the fuel, future oil consumption and emissions will depend crucially on VMT growth. After increasing steadily for several decades, VMT growth slowed and perhaps leveled off in the 2000s before increasing again in the 2010s. The importance of VMT in meeting environmental policy objectives, and the recent dynamics, have raised questions about what factors explain those dynamics and what they imply for future VMT.

Recent studies and public discussion of these dynamics have introduced numerous demographic, economic, and behavioral explanations. In particular, the aging of the population, the economic downturn, and changes in the income distribution, as well as changes in driving habits, could explain the slowdown of VMT growth in the 2000s. However, this research, as well as the extensive literature on gasoline demand and VMT, has not tested these hypotheses in a single framework that distinguishes changes in driving habits from nonlinear relationships among the variables.

We use an Oaxaca-Blinder decomposition and allow for nonlinear relationships among variables. We distinguish between changes in demographics and economic characteristics and in driving habits conditional on demographics and economic characteristics. Demographics and economic characteristics, particularly income and number of workers per household, explain both the slowdown of VMT growth in the 2000s and the apparent growth recovery in the 2010s. Aging of the population made a negative but relatively small contribution to the overall change in VMT. 
The results imply that if the overall stability of aggregate driving habits persists through 2025, VMT will grow at nearly historical rates between 2015 and 2025. The predicted growth rate is smaller than projections from the Energy Information Administration (EIA 2015) but the same as the growth projected by the Federal Highway Administration (FHWA 2015) between 2013 and 2033. Earlier EIA projections of VMT were based primarily on fuel prices and income, but recently EIA revised its VMT projection methodology to include changes in demographics as well as fuel prices and income. Our conclusion that changes in demographics and economic characteristics, rather than in driving habits, explain recent VMT dynamics supports the revised EIA methodology.

Our predictions imply that VMT growth will erode a substantial portion of the fuel savings and greenhouse gas emissions reductions expected under the current U.S. fuel economy and greenhouse gas standards. This conclusion suggests that other policies, such as fuel or carbon taxes, will be needed to change driving habits systematically and reduce average VMT per household. Moreover, the results imply that state policy makers face greater challenges to meeting local air quality standards than if changes in driving habits had permanently reduced VMT growth.

We also document evidence of changes in driving habits for segments of the population, such as for millennials. In the data that are currently available, these segments account for a small share of the population and total VMT. Consequently, habit changes do not substantially affect national VMT. If, however, the habit changes persist over time, the effects of driving habits on future national VMT would be correspondingly greater.

\section{APPENDIX A: NHTS INCOME DATA}

In this appendix, we explain how we handle missing data for income and convert nominal income categories to income categories defined in 1995 dollars. About 10 percent of NHTS households do not report an income category, so we impute incomes for these households based on the incomes of households with similar demographics. To perform this imputation, for each household with a reported income category, we construct a numerical income variable equal to the midpoint of the corresponding income category (for example, numerical income is $\$ 2,500$ for households in the $\$ 0$ to $\$ 5,000$ income category). We assign these households to demographic cells based on the number of workers, household size, MSA size, race category, and education category. For each demographic cell, we compute the average income, and for households with missing income, we impute income using the average income of households in the corresponding demographic cell. ${ }^{13}$

The income categories in the available NHTS data refer to nominal income. The main challenge to using multiple NHTS survey waves is the need to convert the income categories based on nominal income to income categories based on income in 1995 dollars. ${ }^{14}$ To accomplish this, we

13. The definition of the demographic cells used for the income imputation reflects a balance of concerns about measurement error. On the one hand, more narrowly defined cells reduce measurement error because households with missing income are assigned income categories based on more similar households. On the other hand, more narrowly defined cells can increase measurement error because fewer households with reported income are used to impute income for households with missing income. In practice, we impute income for only about 10 percent of households in the sample, and the specific definition of the cells does not appear to affect the main results. The main conclusions in the paper are not affected if we drop observations with imputed income.

14. To illustrate the need for this imputation, consider a household in the 2009 NHTS that reports income between $\$ 75,000$ and $\$ 80,000$, where income is measured in 2009 dollars. We observe only the income category and not the level of income in the data. Suppose that the household has income at the low end of this income category, such as $\$ 76,000$ in 2009 dollars. This income corresponds to $\$ 53,988$ in 1995 dollars, in which case we should assign the individual to the income category of $\$ 50,000$ to $\$ 55,000$ in 1995 dollars. However, if this household has income at the high end of the 2009 NHTS cat- 
take advantage of the fact that the CPS includes income in dollars rather than as a categorical variable. We assign NHTS households to demographic cells based on nominal income category, number of workers, urbanization status, and census division. ${ }^{15}$ We randomly select a CPS household from each corresponding NHTS survey year and cell, and we use that household's income (in 1995 dollars) as the imputed value of income for NHTS households belonging to the corresponding cell. For example, consider a 2009 household with two workers located in an urban area in the West South Central United States. According to the NHTS, this household has an income between $\$ 75,000$ and $\$ 80,000$ (current dollars). A randomly selected CPS household with the same characteristics and nominal income has an income of \$53,421 in 1995 dollars. We assign the NHTS household to the income category of $\$ 50,000$ to $\$ 55,000$ in 1995 dollars. The imputed income in 1995 dollars is then used to assign NHTS households to an income category, using the same $\$ 5,000$ intervals for the real income categories as for the nominal income categories. ${ }^{16}$

\section{APPENDIX B: AGGREGATE ANALYSIS}

For comparison with the Oaxaca-Blinder decomposition, we have performed an analysis of VMT using aggregated state-level data. This appendix describes the results of that analysis.

We aggregate the household-level data in the 1995, 2001, and 2009 NHTS waves by state and year, using sampling weights to weight the observations. Because income is a categorical variable, we convert income to a continuous variable before aggregating. The aggregated data set includes average household VMT, income, respondent age, number of workers, household size, urbanization rate, real gasoline price, number of vehicles, number of drivers, and share of households in each of six MSA size categories.

We estimate a linear regression of average household VMT on the other variables in the aggregated data set. We compute predicted values for each state and year and use the NHTS sample weights to compute the average predicted VMT per household by year. Multiplying average VMT per household by the number of U.S. households yields the predicted national VMT from the statelevel aggregated model.

Appendix Figure 6 compares the predictions from the aggregate model with the baseline estimates using the baseline Oaxaca-Blinder decomposition and NHTS data. The changes in national VMT predicted by the aggregate model between 1995 and subsequent years reflect changes in the underlying explanatory variables over time - that is, changes in demographics and economic characteristics. The aggregate model predicts VMT growth that far exceeds the observed VMT growth, indicating that changes in driving habits between 1995 and 2009 have reduced VMT. The results are similar if we control for macroeconomic conditions, such as by including interest rates, inflation rates, or consumer confidence. Thus, whereas the predicted VMT using the baseline Oax-

egory, such as $\$ 79,000$, then, based on an income of $\$ 56,119$ in 1995 dollars, we should assign the household to the income category of $\$ 55,000$ to $\$ 60,000$ in 1995 dollars. Therefore, observing the household's 2009 NHTS income category does not indicate a unique income category in 1995 dollars. As the text explains, we assign the household an income category based on the income of CPS households that belong to the same cell.

15. The cell definition used for this imputation is different from that used for imputing income for NHTS households with missing income. The definition used for this imputation balances concerns about measurement error noted above, as well as the need to define the cells broadly enough to be able to match all NHTS households to CPS cells.

16. Alternatively, we could compute mean income across CPS households belonging to the same cell as the NHTS household. This approach would yield the same expected value of income as the approach described in the text. We have explored a variety of alternative definitions of the demographic cells that use different sets of variables or different levels of aggregation of the variables. The predicted VMT per household is similar across the alternatives we have considered.

All rights reserved. Copyright (C) 2019 by the IAEE. 
aca-Blinder decomposition suggests that demographics and economic characteristics explain the observed decline in VMT growth after 1995, the aggregate analysis suggests that habits explain the decline.

\section{Appendix Figure 1: Mean Estimated VMT per Household by Income, Number of Workers, or Age Group}

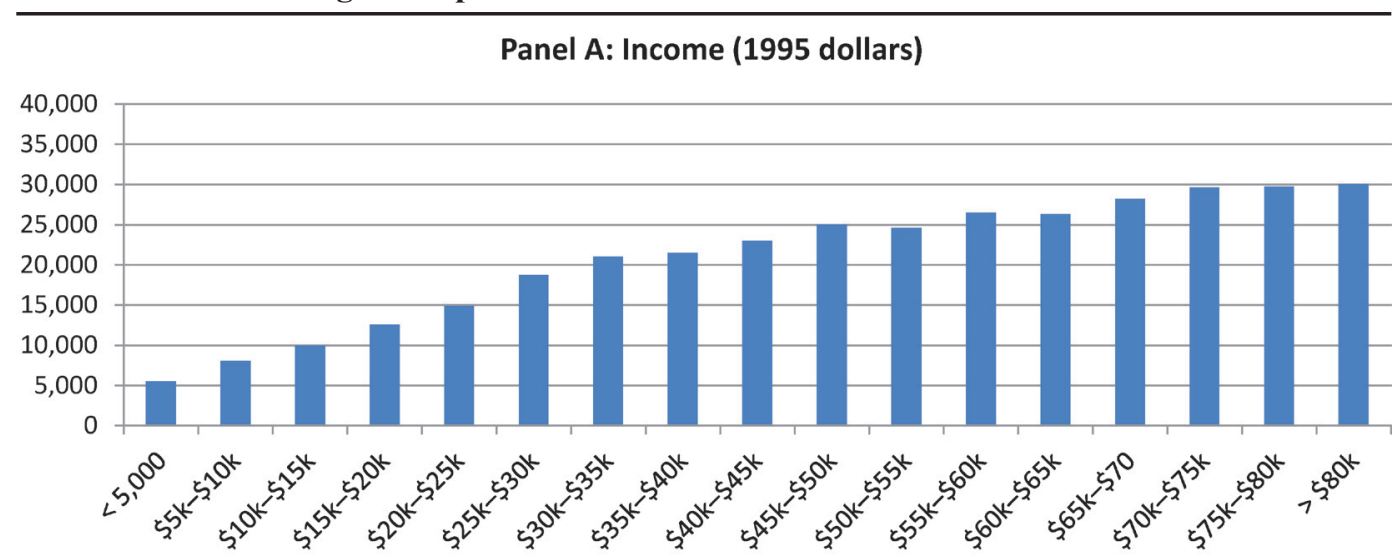

Panel B: Number of Workers

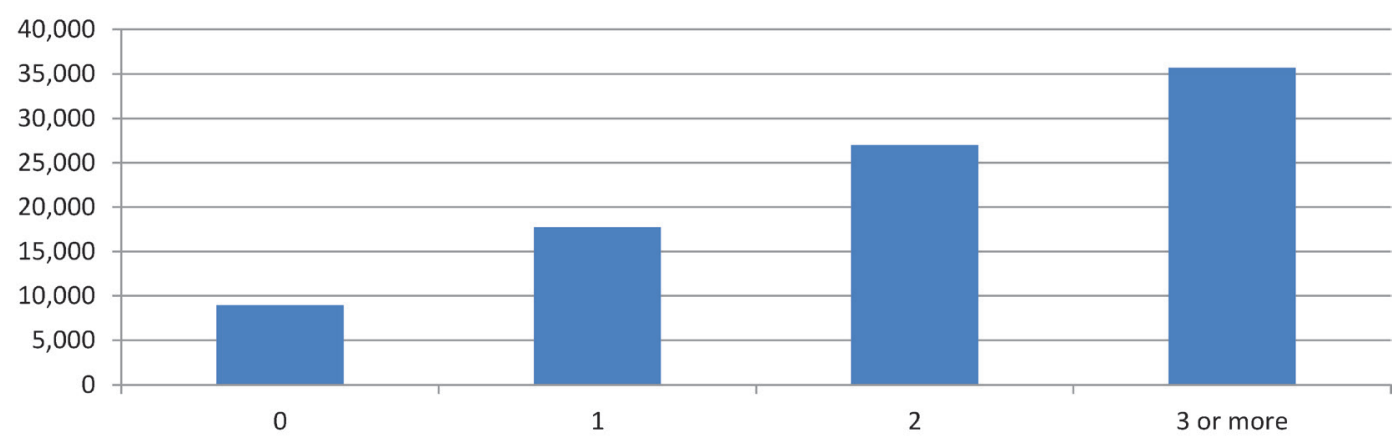

Panel C: Age

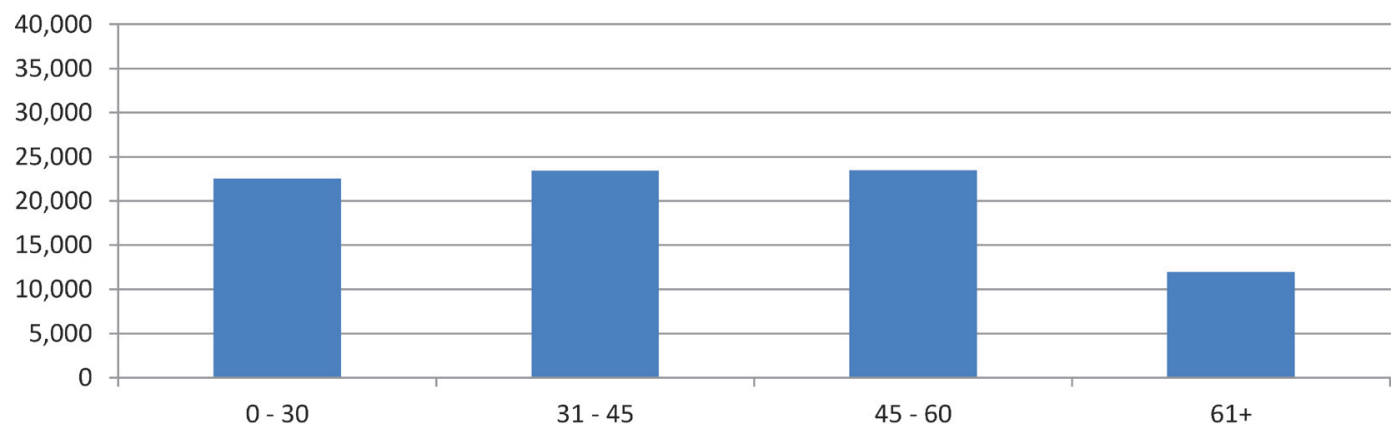

Notes: The figure plots the mean estimated VMT per household by income, number of workers, or age group. The estimates are from equation (3) and are weighted using NHTS survey weights. 
Appendix Figure 2: Alternative Models, CPS

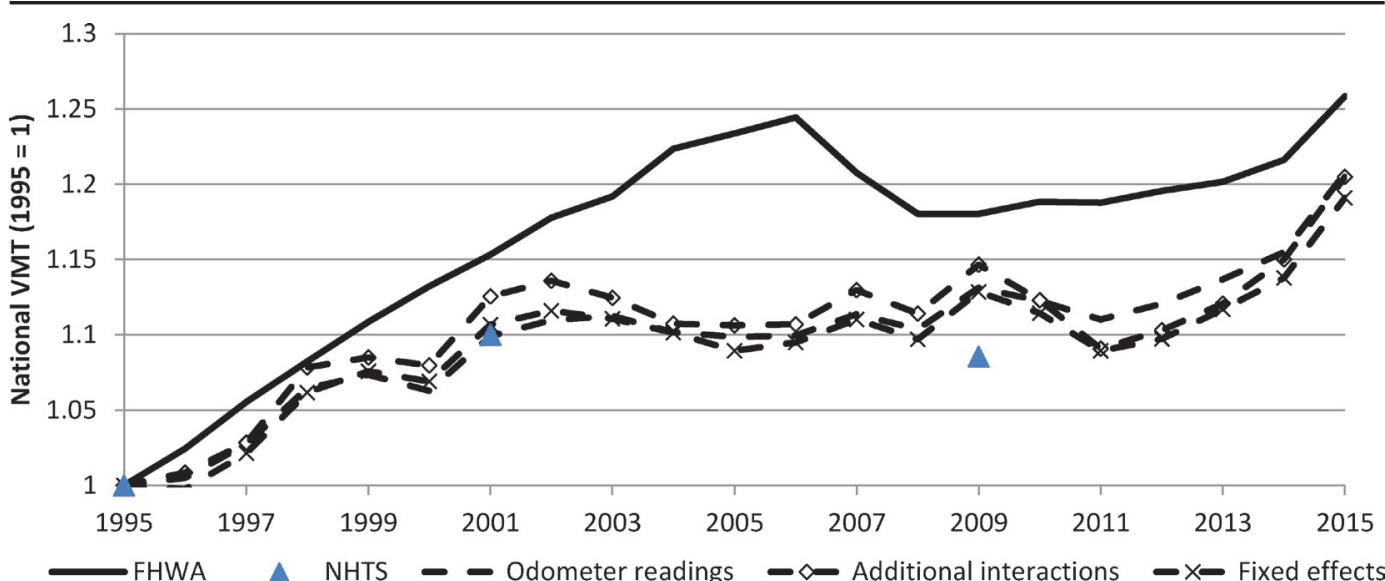

Notes: The FHWA and NHTS data series are the same as in Figure 1. The prediction data series is the predicted national VMT using the 1995 NHTS to predict VMT per household, and using CPS household counts for 1995 through 2015. The VMT per household is predicted as in Figure 5. The series odometer readings uses the NHTS VMT estimated by odometer readings. The series additional interactions uses predicted VMT based on interactions of income category, number of workers, age category, urbanization status, and household size. The series fixed effects uses predicted VMT based on fixed effects for income category, five-year age category, census division, number of workers, education category, household size, race category, and urbanization status instead of the interactions of income category, number of workers, and age category.

\section{Appendix Figure 3: Alternative Gasoline Price Elasticity}

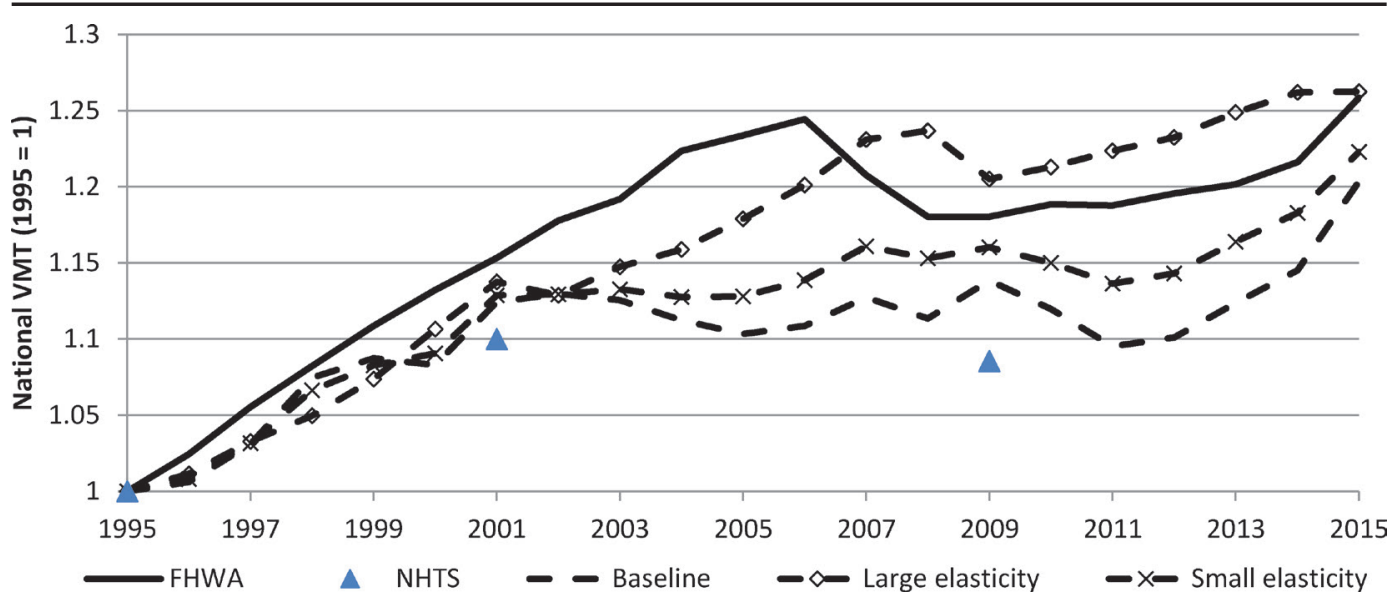

Notes: The baseline is the same as reported in Figure 5. The large and small elasticity series are constructed similarly, except using an elasticity of VMT to gasoline prices of -0.2 or -0.05 rather than the baseline assumption of -0.1 . 


\section{Appendix Figure 4: Comparing Observed and Predicted VMT per Household Using} Estimation Subsamples
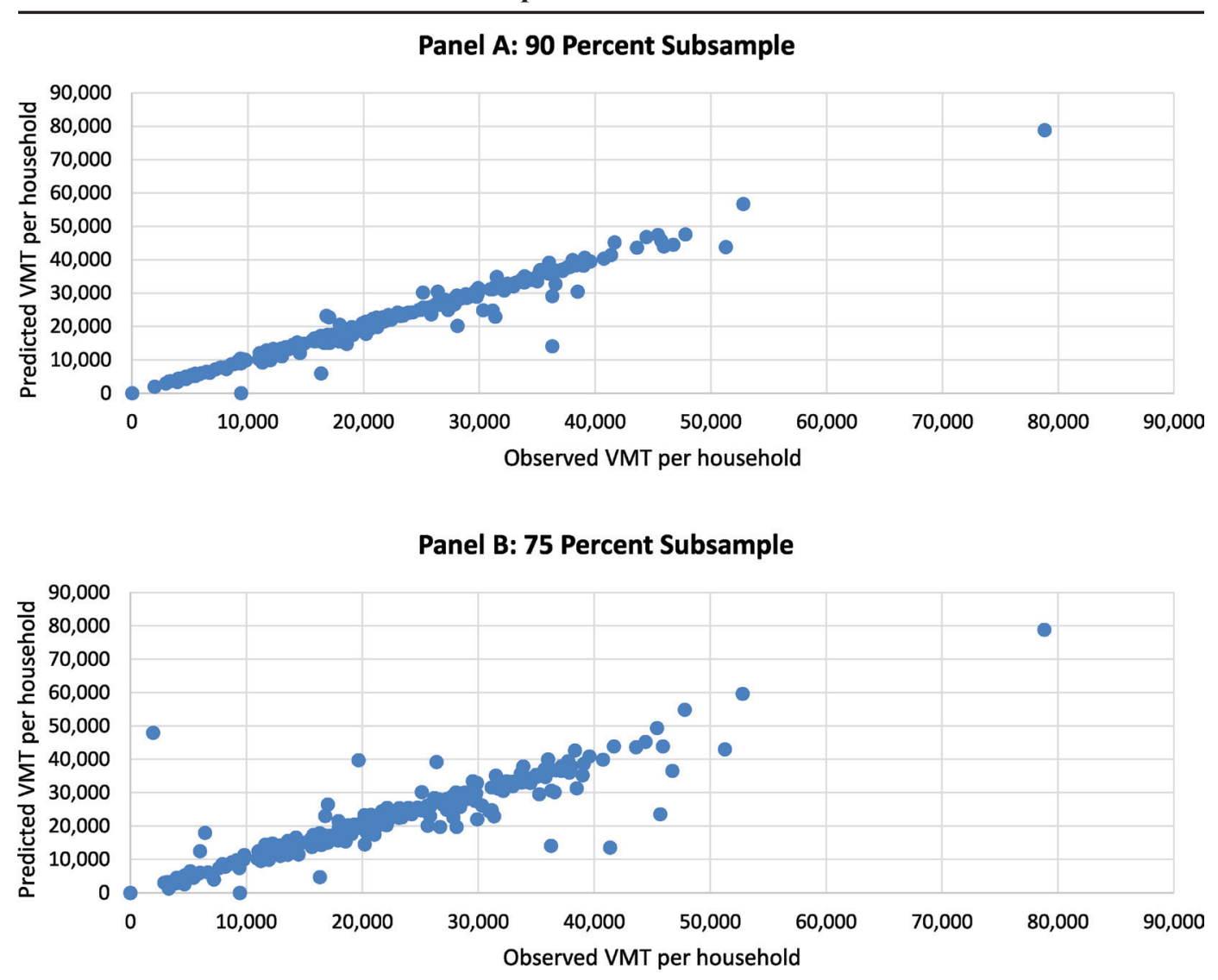

Panel C: 50 Percent Subsample

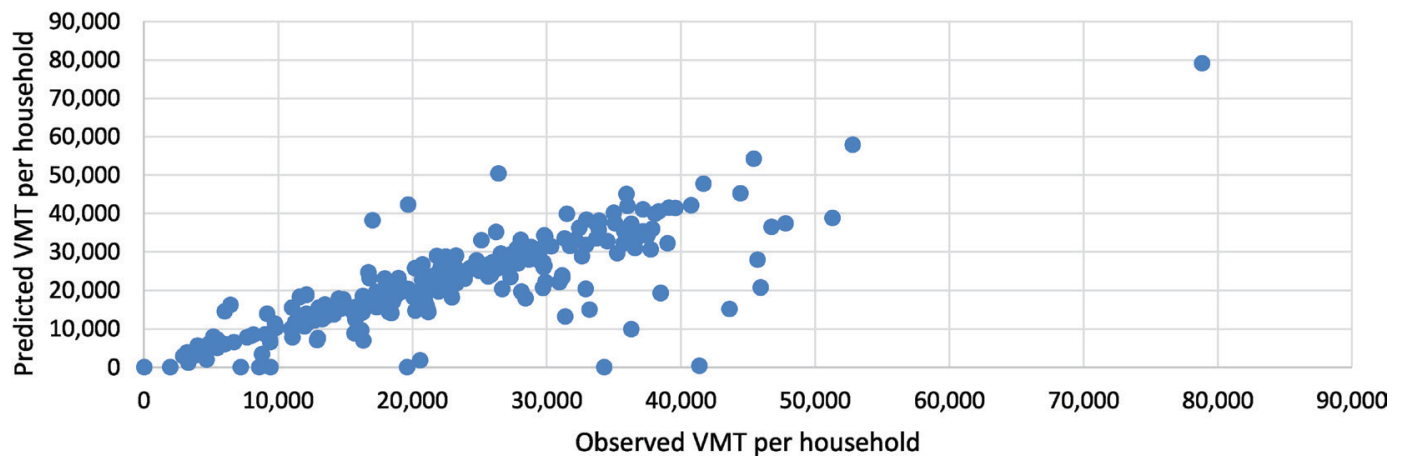

Notes: Each panel plots the predicted VMT per household against the observed VMT per household by group. Predictions use random subsamples of the 1995 NHTS data indicated in the panel titles. 


\section{Appendix Figure 5: Comparing Observed and Predicted VMT per Household Using Linear and Fixed Effects Prediction Models}

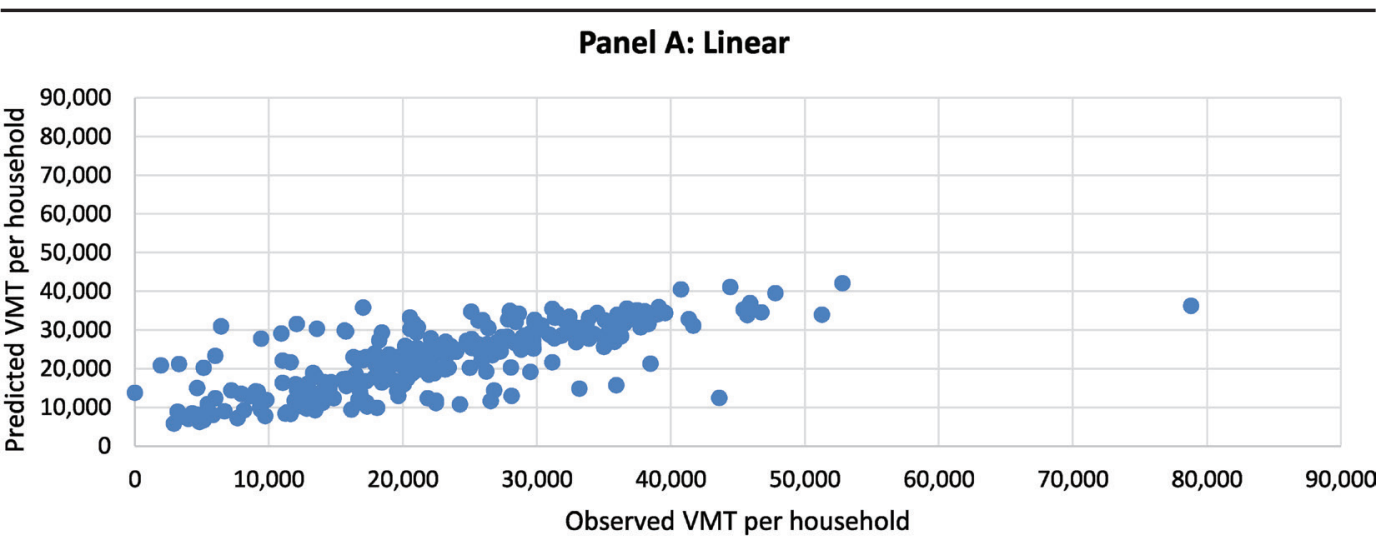

\section{Panel B: Fixed effects}

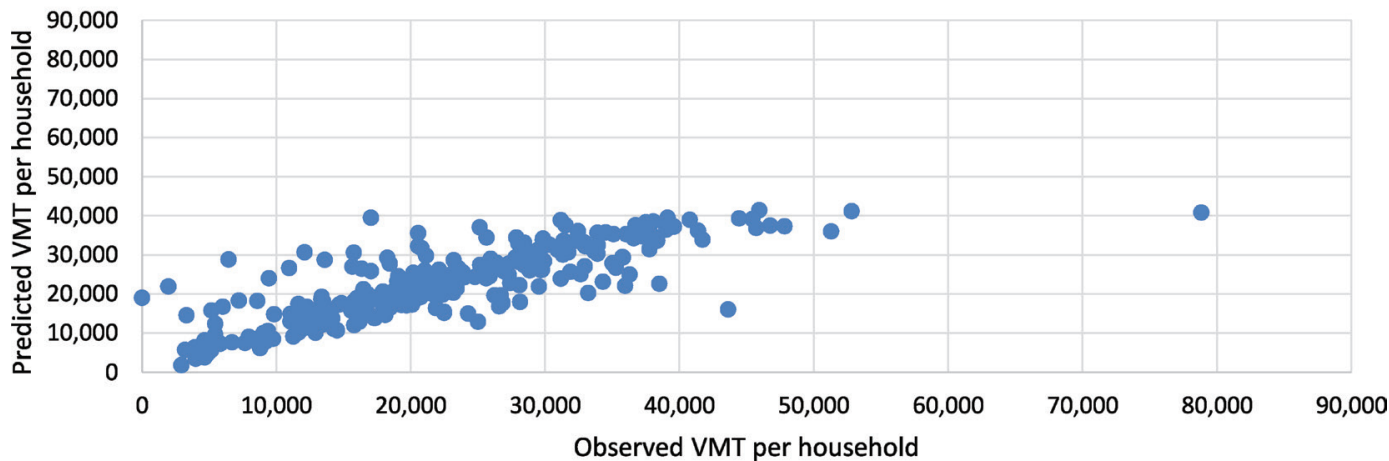

Notes: Each panel plots the predicted VMT per household against the observed VMT per household by group. In Panel A, predictions are computed from a regression of VMT on age, income, and number of workers, rather than on interactions of category fixed effects. In Panel B, predictions are computed from a regression of VMT on fixed effects for age group, income group, and number of household workers.

Appendix Figure 6: Comparison of NHTS, Baseline, and State-Level Aggregate Model

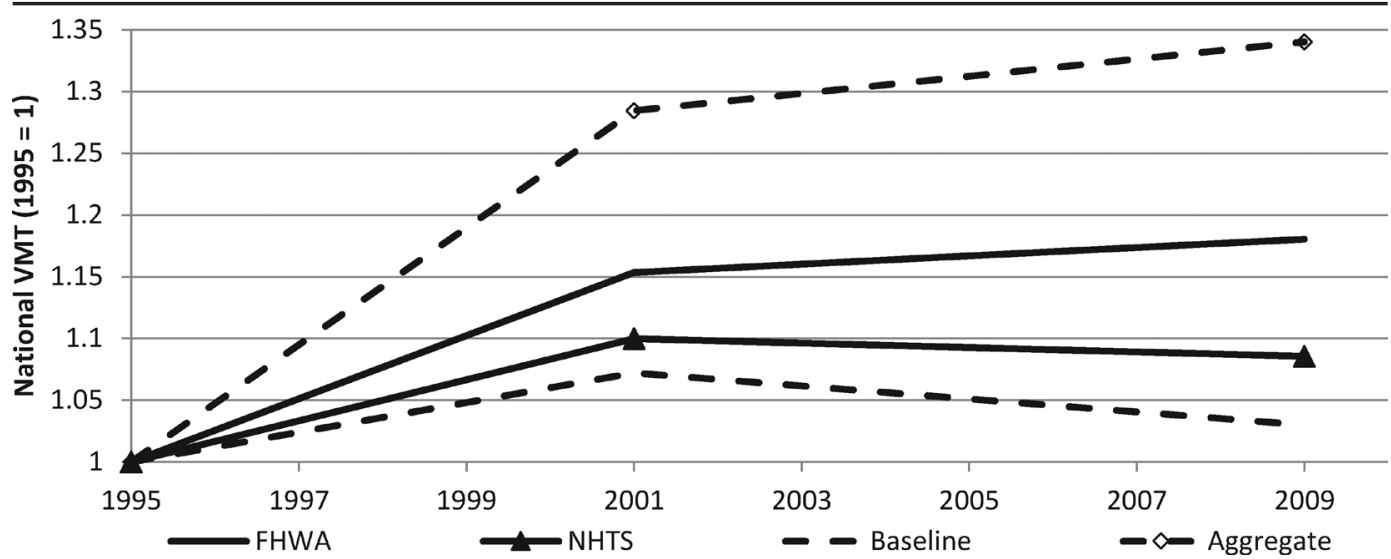

Notes: The FHWA, NHTS, and baseline series are repeated from Figure 5. The state-level model reports the normalized national VMT predicted using state-level data constructed from the 1995, 2001, and 2009 NHTS waves. 


\section{Appendix Figure 7: Comparing Estimated and Predicted VMT Growth, NHTS}

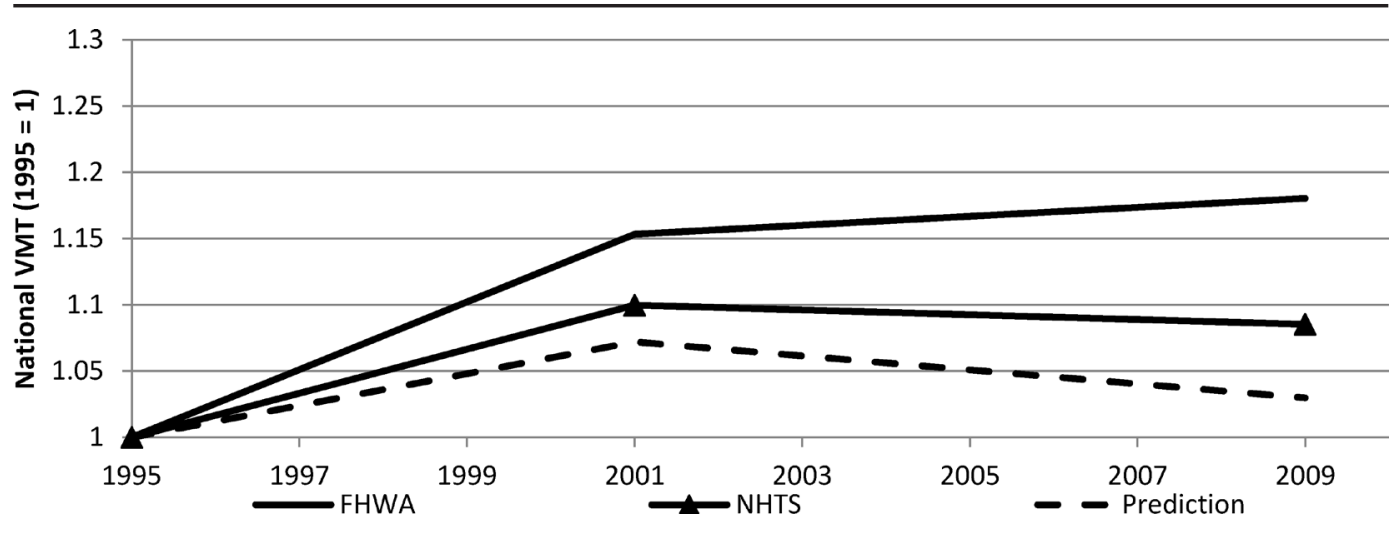

Notes: The FHWA and NHTS data series are the same as in Figure 2. The prediction series is the predicted national VMT using the 1995 NHTS to predict VMT per household, and using NHTS household counts for 1995, 2001, and 2009. The VMT per household is predicted using fixed effects for income category, age category, census division, MSA size by urbanization status, number of workers, number of drivers, number of vehicles, and population density. The fixed effect for income is drawn randomly from demographic groups (categorized by combinations of income, worker count, urbanization status, and census division) constructed using the CPS.

\section{Appendix Figure 8: Alternative Models, NHTS}

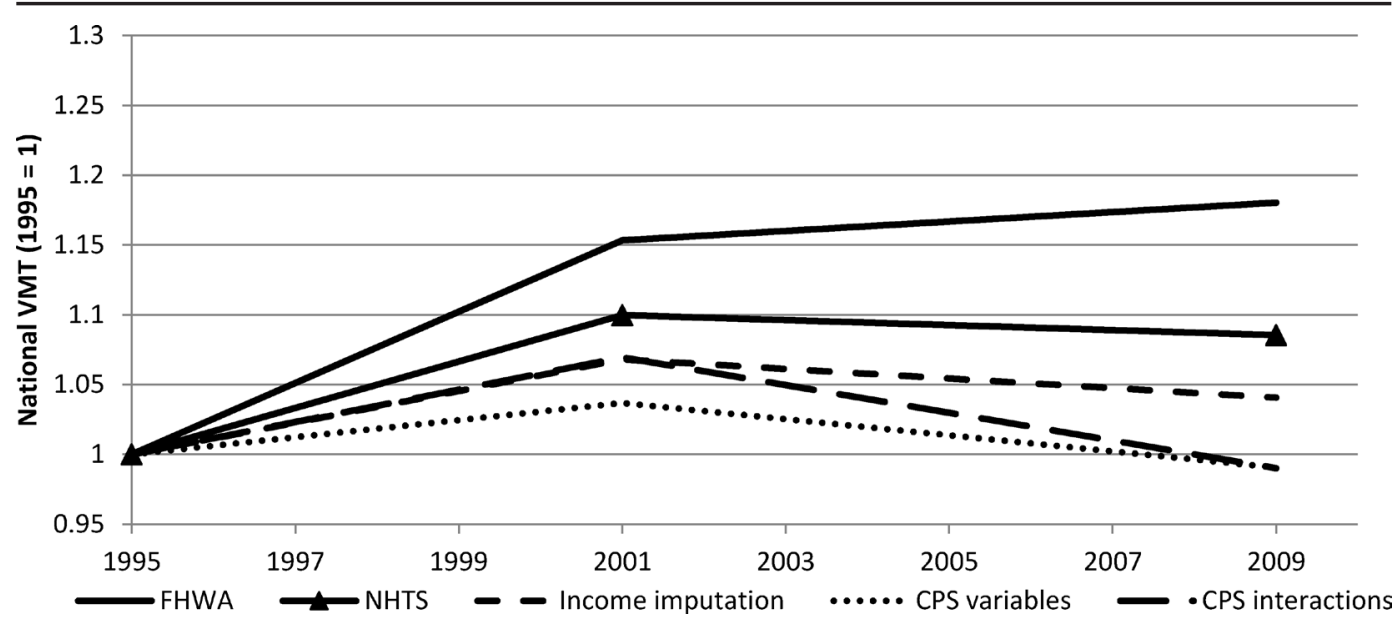

Notes: The FHWA and NHTS data series are the same as in Figure 2. The series income imputation, CPS variables, and CPS interactions are constructed similarly to the prediction series in Appendix Figure 7. Income imputation uses the mean income of CPS households in the same income-worker count-urbanization-census division cell to impute income, rather than the income of a randomly selected CPS household in the same cell. The series CPS variables uses income, age, census division, number of workers, education category, household size, race category, and urbanization status to predict household VMT. The series CPS interactions uses the interaction of income category, age category, and number of workers to predict household VMT.

\section{ACKNOWLEDGMENTS}

We thank Arik Levinson and participants at a Federal Highway Administration workshop for comments on an earlier draft. 


\section{REFERENCES}

Baxandall, P. (2013). Moving Off the Road: A State-by-State Analysis of the National Decline in Driving. Washington, DC: U.S. PIRG Education Fund.

Blinder, A. (1973). "Wage Discrimination: Reduced Form and Structural Estimates." Journal of Human Resources 8(4): 463-55. https://doi.org/10.2307/144855.

Blumenberg, E., B. Taylor, M. Smart, K. Ralph, M. Wander, and S. Brumbagh (2012). What's Youth Got to Do with It? Exploring the Travel Behavior of Teens and Young Adults. Los Angeles: University of California Transportation Center.

Brown, A.E., E. Blumenberg, B.D. Taylor, K. Ralph, and C.A. Voulgaris (2016). "A Taste for Transit? Analyzing Public Transit Use Trends among Youth.” Journal of Public Transportation 19(1): 49-67. https://doi.org/10.5038/2375-0901.19.1.4.

Choo, Sangho, Patricia L. Mokhtarian, and Ilan Salomon (2005). "Does Telecommuting Reduce Vehicle-Miles Traveled? An Aggregate Time Series Analysis for the U.S.” Transportation 32: 37-64. https://doi.org/10.1007/s11116-004-3046-7.

Council of Economic Advisors (CEA) (2014). The Labor Force Participation Rate since 2007: Causes and Policy Implications. Washington, DC.

(2015). Explaining the U.S. Petroleum Consumption Surprise. Washington, DC.

Davis, B., T. Dutzik, and P. Baxandall (2012). Transportation and the New Generation: Why Young People Are Driving Less and What It Means for Transportation Policy. Frontier Group and OSPIRG Foundation.

Department of Transportation (DOT) (2015). Beyond Traffic: Trends and Choices. Washington, DC.

Energy Information Administration (EIA) (2014 and 2015). Annual Energy Outlook 2014 and 2015. Washington, DC: U.S. Department of Energy.

- (2015). Annual Energy Outlook 2015. Washington, DC: U.S. Department of Energy.

Federal Highway Administration (FHWA) (2015). FHWA Forecasts of Vehicle Miles Traveled (VMT): May 2015.

Gillingham, K. (2014). "Identifying the Elasticity of Driving: Evidence from a Gasoline Price Shock in California." Regional Science and Urban Economics 47(4): 13-24. https://doi.org/10.1016/j.regsciurbeco.2013.08.004.

Goldberg, P. K. (1998). "The Effects of the Corporate Average Fuel Efficiency Standards in the US." Journal of Industrial Economics 46: 1-33. https://doi.org/10.1111/1467-6451.00059.

Hughes, J.E., C.R. Knittel, and D. Sperling (2008). "Evidence of a Shift in the Short-Run Price Elasticity of Gasoline Demand." The Energy Journal 29(1): 93-114. https://doi.org/10.5547/ISSN0195-6574-EJ-Vol29-No1-9.

Levinson, A. (2014). “California Energy Efficiency: Lessons for the Rest of the World, or Not?” Journal of Economic Behavior \& Organization 107: 269-89. https://doi.org/10.1016/j.jebo.2014.04.014.

Li, S., J. Linn, and E. Muehlegger (2013). “Gasoline Taxes and Consumer Behavior.” American Economic Journal: Economic Policy 6: 302-42. https://doi.org/10.1257/pol.6.4.302.

Litman, T. (2013). "Changing North American Vehicle-Travel Price Sensitivities: Implications for Transport and Energy Policy.” Transport Policy 28: 2-10. https://doi.org/10.1016/j.tranpol.2012.06.010.

Mans, Janine, Erica Interrante, Lewison Lem, Judy Mueller, and Michael Lawrence (2012). "Next Generation of Travel Behavior: Potential Impacts Related to Household Use of Information and Communication Technology." Transportation Research Record: Journal of the Transportation Research Board 2323: 90-98. https://doi.org/10.3141/2323-11.

McDonald, N. C. (2015). “Are Millennials Really the “Go Nowhere” Generation?” Journal of the American Planning Association 81(2): 90-103. https://doi.org/10.1080/01944363.2015.1057196.

Morikawa, M. (2012). "Population Density and Efficiency in Energy Consumption: An Empirical Analysis of Service Establishments.” Energy Economics 34: 1617-22. https://doi.org/10.1016/j.eneco.2012.01.004.

Oaxaca, R.L. (1973). "Male-Female Wage Differentials in Urban Labor Markets." International Economic Review 14(3): 693-709. https://doi.org/10.2307/2525981.

Polzin, Steven and Xuehao Chu (2014). "Peak Vehicle Miles Traveled and Postpeak Consequences?" Transportation Research Record: Journal of the Transportation Research Board 2453: 22-29. https://doi.org/10.3141/2453-03.

Small, K.A. and K. Van Dender (2007). "Fuel Efficiency and Motor Travel: The Declining Rebound Effect." The Energy Journal 28: 25-51. https://doi.org/10.5547/ISSN0195-6574-EJ-Vol28-No1-2.

U.S. Department of Transportation Federal Highway Administration (FHWA) (2011). Summary of Travel Trends: 2009 National Household Travel Survey. Washington, DC: U.S. Department of Transportation.

Zhai, Q., X. Cao, P.L. Mokhtarian, and F. Zhen (2017). “The Interactions between E-Shopping and Store Shopping in the Shopping Process for Search Goods and Experience Goods.” Transportation 44 (5): 885-904. https://doi.org/10.1007/ s11116-016-9683-9.

Zhou, Y. and X. Wang (2014). "Exploring the Relationship between Online Shopping and Shopping Trips: An Analysis with the 2009 NHTS Data.” Transportation Research Part A: Policy and Practice 70: 1-9. https://doi.org/10.1016/j. tra.2014.09.014.

All rights reserved. Copyright (C) 2019 by the IAEE. 